\title{
New Monetarist Economics: Methods
}

\author{
Stephen Williamson and Randall Wright
}

This essay articulates the principles and practices of New Monetarism, the authors' label for a recent body of work on money, banking, payments, and asset markets. They first discuss methodological issues distinguishing their approach from others: New Monetarism has something in common with Old Monetarism, but there are also important differences; it has little in common with Keynesianism. They describe the principles of these schools and contrast them with their approach. To show how it works in practice, they build a benchmark New Monetarist model and use it to study several issues, including the cost of inflation, liquidity, and asset trading. They also develop a new model of banking. (JEL E0, E1, E4, E5)

Federal Reserve Bank of St. Louis Review, July/August 2010, 92(4), pp. 265-302.

\section{INTRODUCTION}

T he purpose of this essay is to articulate the principles and practices of a school of thought we call New Monetarist

Economics. It is a companion piece to Williamson and Wright (forthcoming), which provides more of a survey of the models used in this literature and focuses on technical issues to the neglect of methodology or history of thought. Although we do present some technical material in order to show how the approach works in practice, here we also want to discuss in more detail what we think defines New Monetarism. ${ }^{1}$ Although there is by now a large body of research in the area,

\footnotetext{
1 The other paper is forthcoming as a chapter for the new Handbook of Monetary Economics, edited by Benjamin Friedman and Michael Woodford, and early versions included much of the discussion contained here. But to keep the chapter focused, on the advice of the editors, we separated the material into two papers. There is unavoidably some overlap in the presentations, since the same
}

perhaps our labeling of it merits explanation. We call ourselves New Monetarists because we find much that is appealing in Old Monetarist economics, epitomized by the writings of Milton Friedman and his followers, although we also disagree with some of their ideas in important ways. We have little in common with Old or New Keynesians, in part because of the way they approach monetary economics and the microfoundations of macroeconomics and in part because of their nearly exclusive focus on nominal rigidities as the key distortion shaping policy. Below we describe in more detail what we see as the defining principles of these various schools and try to differentiate our approach.

benchmark model is developed in both, but the applications are different, and there remains almost no discussion of how our approach compares to alternative schools of thought in the Handbook chapter. In this essay, we try explain what we think our methods are, not just how our models work.

\footnotetext{
Stephen Williamson is a professor of economics at Washington University in St. Louis, a visiting scholar at the Federal Reserve Bank of Richmond, and a research fellow at the Federal Reserve Bank of St. Louis. Randall Wright is a professor of economics at the University of Wisconsin-Madison, and a research associate at the Federal Reserve Bank of Minneapolis. The authors thank many friends and colleagues for useful discussions and comments, including Neil Wallace, Fernando Alvarez, Robert Lucas, Guillaume Rocheteau, and Lucy Liu. They thank the National Science Foundation for financial support. Wright also thanks for support the Ray Zemon Chair in Liquid Assets at the Wisconsin Business School.

(C) 2010, The Federal Reserve Bank of St. Louis. The views expressed in this article are those of the author(s) and do not necessarily reflect the views of the Federal Reserve System, the Board of Governors, or the regional Federal Reserve Banks. Articles may be reprinted, reproduced, published, distributed, displayed, and transmitted in their entirety if copyright notice, author name(s), and full citation are included. Abstracts, synopses, and other derivative works may be made only with prior written permission of the Federal Reserve Bank of St. Louis.
} 
One reason to do so is the following: We think that it was a healthy state of affairs when, even in the halcyon days of Old Keynesianism, there was a dissenting view presented by Old Monetarists. At the very least, this dissenting view could be interpreted as a voice of caution to those who thought that macro and monetary economics back in the day were solved problems-which obviously looks premature with the benefit of hindsight. ${ }^{2}$ The claim that people thought the problems were solved is well documented by the sentiments of Solow as quoted by Leijonhufvud (1968), when he said,

I think that most economists would feel that short-run macroeconomic theory is pretty well in hand...The basic outlines of the dominant theory have not changed in years. All that is left is the trivial job of filling in the empty boxes, and that will not take more than 50 years of concentrated effort at a maximum.

At least prior to recent events, many people seemed to be of the opinion that there was a New Keynesian consensus, similarly sanguine as in the 1960s. We feel that it would be healthier if currently more people recognized that there is an alternative to New Keynesianism. We dub our alternative New Monetarism.

Evidence that people have an impression of consensus, at least among more policy-oriented economists, about the idea that New Keynesianism is the most useful approach to analyzing macroeconomic phenomena and guiding central bank policy can be found in many places (see, e.g., Goodfriend, 2007). We find this somewhat surprising, mainly because we encounter much sympathy for the view that there are fundamental flaws in the New Keynesian framework. It must then be the case that those of us who think New Keynesianism is not the only game in town, or who think that the approach has some deep issues that need to be discussed, are not speaking with enough force and clarity. In part, this essay is an attempt to rectify this state of affairs and foster

\footnotetext{
2 Rather than go through the details, we refer to Lucas (1980a) for a discussion of how the paradigm of the 1960s was disrupted by the confluence of events and technical developments in the 1970s, leading to the rise of the rational expectations, or New Classical, approach to macroeconomics.
}

more healthy debate. The interaction we envision between New Monetarists and New Keynesians is in some ways similar to the debates in the $1960 \mathrm{~s}$ and 1970s, but it is in other ways different, of course, since much of the method and language has changed in economics since then. To bring the dialog to the twenty-first century, we need to describe what New Monetarists are doing and why we are doing it.

New Monetarism encompasses a body of research on monetary theory and policy, banking, financial intermediation, payments, and asset markets, developed over the past few decades. In monetary economics, this includes the seminal work using overlapping generations models by Lucas (1972) and some of the contributors to the Kareken and Wallace (1980) volume, although antecedents exist, including, of course, Samuelson (1958). More recently, much monetary theory has adopted the search and matching approach, an early example of which is Kiyotaki and Wright (1989), although there are also antecedents for this, including Jones (1976) and Diamond (1984). In the economics of banking, intermediation, and payments, which builds on advances in information theory that occurred mainly in the 1970s, we have in mind papers such as Diamond and Dybvig (1983), Diamond (1984), Williamson (1986 and 1987a), Bernanke and Gertler (1989), and Freeman (1996). On asset markets and finance we have in mind recent work such as Duffie, Gârleanu, and Pederson (2005) or Lagos and Rocheteau (2009). Much of this research is abstract and theoretical, but attention has turned more recently to empirical and policy issues. ${ }^{3}$

To explain what unifies this work, we begin in Section 1 by saying what New Monetarism is not, describing what we see as the defining characteristics of other schools. Then we lay out a set of principles that guide our approach. By way of preview, we think New Monetarists agree more or less with the following:

Principle 1. Microfoundations matter, and productive analyses of macro and monetary economics,

\footnotetext{
3 The examples cited here are meant only to give a broad impression of the kind of research we have in mind. More examples and references are found below.
} 
including policy discussions, require adherence to sound and internally consistent economic theory.

Principle 2. Money matters, and in the quest to understand monetary phenomena and monetary policy, it is decidedly better to use models that are explicit about the frictions that give rise to a role for money in the first place; as Wallace (1998) puts it, money should not be a primitive in monetary economics.

Principle 3. Financial intermediation matterse.g., while bank liabilities and currency sometimes perform similar roles as media of exchange, for many issues treating them as identical can lead one astray.

Principle 4. In modeling frictions, like those that give rise to a role for money or financial intermediaries, one has to have an eye for the appropriate level of abstraction and tractability-e.g., the fact that in some overlapping generations models people live two periods, or that in some search models people meet purely at random, may make them unrealistic but it does not make them irrelevant.

Principle 5. No single model should be an allpurpose vehicle for dealing with every question in monetary economics, but it is still desirable to have a framework, or a class of models making use of similar assumptions and technical devices, that can be applied to a variety of issues.

That these principles are not all universally accepted is to us only too clear. Consider Principle 2 (money matters). This is violated by the many currently popular models used for monetary policy analysis that either have no moneyor banks or related institutions-or, if they do, they slip it in by assuming cash-in-advance constraints or by putting money in utility or production functions or even putting government bonds and commercial bank reserves in utility or production functions. ${ }^{4}$ Also, while some of these principles may be accepted in principle by most

\footnotetext{
4 See Krishnamurthy and Vissing-Jorgensen (2009) and Curdia and Woodford (2009) for recent examples of T-Bills or bank reserves showing up in utility or production functions. We are not here arguing that taking such shortcuts isn't time-honored (see Tobin 1958) or that it is never useful. The claim is that this is not what a New Monetarist would do on a good day.
}

economists, it is a matter of degree. Consider Principle 4 (appropriate abstraction). We all learn, or at least teach, that useful economic models are not necessarily realistic, but one still hears rather harsh critiques of both overlapping generations and search models of money based primarily on their lack of realism. ${ }^{5}$ Also, we don't want Principle 1 (microfoundations matter) to sound like a platitude, even if everyone, of course, wants sound and consistent economic theory-or at least they pay lip service to this-as we believe New Monetarists take it more seriously. Not to pick too much on any one example, for now, but consider the so-called fiscal theory of the price level. New Keynesians seem to find this quite interesting despite the fact that it typically relies on descriptions of what happens out of equilibrium, in models that have nothing to say except about what happens in equilibrium. This is something that would bother a New Monetarist a lot. ${ }^{6}$

A more obvious illustration of New Monetarists worrying relatively more about the soundness and consistency of economic theories may be the reliance of the entire Keynesian edifice on a foundation of sticky prices, which are not what we would call microfounded, even whenespecially when-appeal is made to Calvo (1983) pricing or Mankiw (1985) menu costs. This may not be the place to go too far into a discussion of the merits or demerits of imposing nominal rigidities, and given the readiness of many economists to adopt stickiness with neither trepidation nor apology, we can't imagine changing anyone's mind easily. But in Williamson and Wright (forthcoming) we offer as food for thought two New Monetarist models that speak to the issue. In one, we blatantly impose price stickiness to yield a version of our framework that looks in many ways like what one sees in Woodford (2003) or Clarida, Gali, and Gertler (1999). This is intended to show that, even if one cannot live without nominal

5 See Tobin (1980) and Howitt (2005) for negative takes on overlapping generations and search models, based on the unrealistic assumptions of two-period-lived agents and random matching, respectively.

6 Bassetto (2002) is a notable exception because he does not use classical equilibrium theory to discuss what happens out of equilibrium. 
rigidity, this does not mean one cannot be serious about money, banking, and related institutions. The other model uses search theory to get nominal rigidities to emerge endogenously, as an outcome rather than an assumption. This model is consistent not just with the broad observation that many prices appear to be sticky, but also the detailed micro evidence discussed by Klenow and Malin (forthcoming) and references therein. Yet it delivers policy prescriptions very different from those of New Keynesians: Money is neutral. We return to some of these issues below, but the point here is that sticky prices do not logically constitute evidence of nonneutralities or support for Keynesian policy. ${ }^{7}$

The rest of the paper is organized as follows. In Section 2 we go into detail concerning what we think New Monetarism is and how it compares with other approaches. In Section 3, in the spirit of Principle 5 above, we lay out a very tractable New Monetarist benchmark model based on Lagos and Wright (2005). We try to explain what lies behind the assumptions and we give some of its basic properties-money is neutral but not superneutral, the Friedman rule is optimal but may not give the first best, and so on. In Section 4 we discuss a few extensions of the baseline model that can be found in the literature. Then we show how these models can be used in novel ways to address issues pertaining to asset markets, banking, and monetary policy. In Section 5 we construct a model with money and equity shares and discuss its implications for asset pricing, asset trading, and liquidity premia, including how these depend on monetary policy. This model is extended in Section 6 to include banking, in order to show how financial intermediation can improve welfare and to derive some new results concerning the effect of monetary policy on interest rates. This illustrates one way in which New Monetarism

\footnotetext{
7 The model we are referring to is based on Head et al. (2010), which is related to, but also quite different from Caplin and Spulber (1987). To be clear, the New Monetarist position is not that monetary nonneutralities can never arise, and indeed we provide examples where they do (based, e.g., on incomplete information), nor is it our position that policy is irrelevant, as in some examples from New Classical macro (e.g., Sargent and Wallace, 1975, 1976). The point is rather that, despite what one hears from pundits such as Ball and Mankiw (1994), as a matter of logic, nominal rigidities in theory do not mean Keynesians are right in practice.
}

departs from Old Monetarism: Friedman's proposal for 100 percent reserve requirements is a bad idea, according to this model, because it eliminates the welfare gains from intermediation, exemplifying Principle 3 above. We conclude in Section 7.

We think that the examples presented here and in Williamson and Wright (forthcoming) illustrate the usefulness of the New Monetarist approach. As we hope readers will appreciate, the models used in different applications all build on a consistent set of economic principles. This is true of the simplest setups used to formalize the role of currency in the exchange process, and of the extensions to incorporate banking, credit arrangements, payment systems, and asset markets. We think this is not only interesting in terms of theory, but there are also lessons to be learned for understanding the current economic situation and shaping future policy. To the extent that the recent crisis has at its roots problems related to banking, to mortgage and other credit arrangements, or to information problems in asset markets, one cannot hope to address the issues without theories that take seriously the exchange process. Studying this process is exactly what New Monetarist economics is about. Although New Keynesians have had some admirable success, perhaps especially in convincing policymakers to listen to them, we are not convinced that all economic problems are caused by nominal rigidities. And despite the views of reactionaries such as Krugman (2009), we cannot believe the answer to every interesting question hangs on the Old Keynesian cross. We think our approach provides a relevant alternative for academics and policymakers, and what follows is an attempt to elaborate on this position.

\section{PERSPECTIVES ON MONETARY ECONOMICS}

To explain the basic precepts underlying New Monetarism, we find it helps to first summarize some popular alternative schools of thought. This will allow us to highlight what is different about our approach to understanding monetary phenomena and guiding monetary policy. 


\subsection{Keynesianism}

We begin with a discussion of Keynesian economics, ostensibly to describe what it is, but, we have to admit, also partially to critique it. Of course, it all began with Keynes's (1936) General Theory. His ideas were soon popularized in Hicks's (1937) IS-LM model, which became enshrined in the undergraduate curriculum and was integrated into the so-called Neoclassical Synthesis of the 1960s. New Keynesian economics, as surveyed in Clarida, Gali, and Gertler (1999) or Woodford (2003), makes use of more sophisticated tools than Old Keynesian economists had at their disposal, but much of the language and many of the ideas are essentially the same. New Keynesianism is typically marketed as a synthesis that can be boiled down to an IS relationship, a Phillips curve, and a policy rule determining the nominal interest rate, the output gap, and the inflation rate. It is possible to derive a model featuring these equations from slightly more primitive ingredients, including preferences, but often practitioners do not bother with these details. If one were being pedantic one could find this problematic, since reduced-form relations from one model need not hold once one changes the environment, but we don't want to dwell on self-evident points.

A more serious concern is that all New Keynesian models have weak foundations for the ingredient at the very core of the theory: Prices (or sometimes wages) must be set in nominal terms, even in nonmonetary versions, mind you, and these prices are sticky in the sense that they cannot be changed, except at times specified rather arbitrarily, or at a cost. We already discussed some issues related to nominal rigidities in the Introduction, and rather than repeat that material here, we mention a few other points. First, as everyone including any card-carrying Keynesian is well aware, the key implications of the theory would be completely overturned if nominal prices could be indexed to observables, say if a seller announces "my price in dollars is $p$ and it increases one-forone with aggregate $P$." Such a scheme does not seem especially complicated or costly-to miss this trick, one has to be not merely rationally inattentive but a veritable slug. Having said that, we are all for the idea that information processing may be costly, consistent with the "sticky information" approach suggested by Mankiw and Reis (2002), even if we find the label sticky information, to mix metaphors, pandering to the choir. We are not sure, however, that when all is said and done the most relevant manifestation of information-processing costs will be that Keynes turned out to be right.

Another issue is this: Economists take many ingredients as given, including preferences, endowments, and technology. Why not treat other things the same way and take sticky prices, or, more generally, incomplete contracts or incomplete markets, as given? One answer is it depends on the question. But from this perspective, taking nominal rigidities as given is delicate when they are the essential component of the theory and the main driver of its policy prescriptions. Another answer is one that we think we heard suggested by Neil Wallace ( he may disavow it). Economists have others to study preferences, endowments, and technology_-including psychologists, resource specialists, and engineers-and they can at least potentially inform us about those elements of the world. We might hope to get away with deferring to others, in saying we take those things as given, since they are not our area of expertise. But the pricing mechanism, including nominal stickiness and more generally incomplete markets and contracts, is exactly the thing we ought to be studying. Almost by definition, there is no one but economists to chime in on these elements. When we take them as given we are surely shirking. ${ }^{8}$

Another point is that we object to calling sticky prices a "friction," and this is only partly semantic. We think of frictions as features of the environment that make it difficult for agents in the

8 A different but related idea is that, if we are going to allow menu costs to muck up the process of changing prices, we ought to take seriously the costs of changing everything, and we don't mean merely tacking on ad hoc costs of adjustment in capital, inventories, and employment. If this is not obvious, consider the following. At some level we might all agree that search theory is a type of adjustment-cost theory, yet one can still claim that for many purposes it is more fruitful to use explicit search-based models of the labor market than otherwise frictionless models with some parametric cost-of-adjustment specification. As always, this will depend on the issue at hand, and perhaps also on taste or faith, but in our opinion what we learn from the successes (and the failures!) of search-based models of labor markets speaks for itself. 
model to achieve desirable outcomes. Examples include private information or limited commitment, which may make it difficult to get agents to tell the truth or keep their promises; spatial or temporal separation, which can make it hard for agents to get together in the first place; and problems like imperfect monitoring, incomplete record keeping, and so on. These are, to repeat, frictions in the environment. By contrast, price stickiness is, if anything, a friction in the mechanism. It interferes directly with the way agents behave, as opposed to letting them interact as they like subject to constraints imposed by endowments, technology, preferences, and frictions in the environment as mentioned above. A serious, and not just semantic, reason to distinguish between frictions in the environment and the mechanism is that agents, in both our world and our models, should be allowed to be creative and resilient when it comes to seeking out gains from trade.

What we mean is this: In some environments, competitive equilibrium and alternative solution concepts, like the core, generate the same outcomes, so it does not matter which we use. However, once we make prices or wages sticky, say using Calvo (1983) pricing or Mankiw (1985) costs, these mechanisms are generally not equivalent. In a world where market prices are sticky, agents may well choose endogenously to adopt an alternative trading mechanism that delivers superior outcomes. One early version of this notion was the suggestion by Barro (1977) that sticky wages may be nothing more than a facade. An earlier version is Coase's (1937) theory of firm formation. In all these cases, the big idea is that when the price mechanism is doing a relatively poor job, agents will abandon it and start interacting via alternative institutions. An implication we find unattractive (although we understand that this is what some people like the most) in sticky-price theory is that agents in the model are not doing as well as they could: Gains from trade are being left on the table when exchanges are forced at the wrong relative prices. The modelers who use this approach are only allowing agents to do the best they can from a very narrow perspective, taking institutions as given, as if microfoundations means it is enough to let agents solve any old constrained maximization problem.
This is in sharp contrast to some economic theory, the purest of which we take to be the mechanism design approach, where, by construction, agents do as well as they can subject to constraints imposed by the environment and incentive conditions. There can be frictions, including private information or limited commitment, of course, that make doing as well as one can fairly bad. It would be a rookie mistake to think that the practitioners of mechanism design believe we live in a Panglossian world, as Buiter (1980) once said of New Classical macroeconomists. The world could be better with fewer constraints (and, indeed, sometimes it would be better with more constraints). We find it appealing that mechanism design attributes creativity and resiliency to the agents in models. We also find it interesting that economists often proceed as though agents can figure out how to interact optimally in the presence of moral hazard, adverse selection, and other recalcitrant situations, and yet at other times they proceed as if these agents can't get their heads around the comparatively minor inconvenience of a tardy Calvo fairy.

We do not want to push the whole mechanism design approach too hard here, and since we do not have the space, anyway, we refer to Wallace (forthcoming), which is another Handbook of Monetary Economics chapter, and is dedicated to the topic. ${ }^{9}$ We do want to mention Townsend (1988), however, who put it this way:

The competitive markets hypothesis has been viewed primarily as a postulate to help make the mapping from environments to outcomes more precise...In the end though it should be emphasized that market structure should be endogenous to the class of general equilibrium models at hand. That is, the theory should explain why markets sometimes exist and sometimes do not, so that economic organisation falls out in the solution to the mechanism design problem. (pp. 22-23)

Nominal rigidities, like incomplete markets or contracts, more generally, might conceivably

\footnotetext{
9 We do think there are some subtle unresolved issues, like whether a given bargaining protocol should be considered part of the environment or a particular imposed mechanism (see Hu, Kennan, and Wallace, 2009).
} 
emerge endogenously out of some environments, but we think it would be better if they were an outcome and not an assumption, especially since in Keynesian economics everything hinges on such rigidities. The Introduction discussed a case where sticky prices emerged endogenously that did not support the Keynesian position. ${ }^{10}$

But we digress. And we are perhaps being too negative. Despite the above concerns, which may sound like nit picking to many people, New Keynesianism has met with considerable success, obviously. It is also sometimes argued that it is consistent with, or has absorbed, the major revolutionary ideas developed in macroeconomics over the past few decades, including the Lucas critique and real business cycle theory, though this is somewhat less obvious. If we take Woodford (2003) as representing the state of the art, the main tenets of the approach are the following:

(1) The key friction that gives rise to shortrun nonneutralities of money, and the primary concern of central bank policy, is sticky prices. Because some prices are not fully flexible, inflation or deflation induces relative price distortions, and this has consequences for welfare. There can be other distortions, such as monopolistic as opposed to perfect competition, or non-lump-sum taxes, in some applications, but nominal rigidities are clearly the essence of the approach.

(2) The frictions that we encounter in relatively deep monetary economics, or even not-so-deep monetary economics, like cash-in-advance models, are at best of second-order importance. In monetary theory these frictions include explicit descriptions of specialization that make direct exchange difficult, and information

\footnotetext{
${ }^{10}$ Relatedly, speaking more directly about money and banking, a position advocated in Williamson (1987b), is that what makes financial intermediation potentially worth studying are its special functions, such as diversification, information processing, and asset transformation. We cannot expect to generate these special activities or derive many useful implications if our approach does not build on the economic features that cause financial intermediaries to arise in the first place. This is another call for making one's assumptions explicit and generating market structure, including everything from intermediation to nominal contracting, endogenously.
}

problems that make credit difficult, giving rise to a fundamental role for media of exchange and to different implications for policy.

(3) There is a short-run Phillips curve tradeoff between inflation and output (if not inflation and unemployment, since these theories typically do not have detailed descriptions of the labor market, with exceptions like Gertler and Trigari, 2009). We can induce a short-run increase in output with an increase in inflation.

(4) The central bank is viewed as being able to set a short-term nominal interest rate, and the policy problem is presented as the choice over alternative rules for how this should be done in response to current economic conditions.

We also think it is fair to say that New Keynesians tend to be supportive of current practice by central banks. Elements of the modeling approach in Woodford (2003) are specifically designed to match standard operating procedures, and he appears to find little in the behavior of central banks that he does not like. The feeling seems to be mutual, which may be what people envisage when they conclude that there is a consensus. Interest in New Keynesianism has been intense in recent years, especially in policy circles, and as we said above, some economists (again, see Goodfriend, 2007) profess that it constitutes the default approach to analyzing and evaluating monetary policy.

\subsection{Monetarism}

Old Monetarist ideas are represented in the writings of Friedman (1960, 1968, and 1969) and Friedman and Schwartz (1963). In the 1960s and 1970 s, the approach was viewed as an alternative to Keynesianism, with different implications for how policy should be conducted. Friedman put much weight on empirical analysis and the approach was often grounded only informally in theory-even if some of his work, such as the theory of the consumption function in Friedman (1957), is concerned with what we would call 
microfoundations. Although there are few professed monetarists in the profession these days, the school has had an important role in shaping macroeconomics and the practice of central banking. ${ }^{11}$

The central canons of Old Monetarism include the following:

(1) Sticky prices, while possibly important in generating short-run nonneutralities, are unimportant for monetary policy.

(2) Inflation, and inflation uncertainty, generate significant welfare losses.

(3) The quantity theory of money is an essential building block. There exists a demand function for money which is an empirically stable function of a few variables.

(4) There may exist a short-run Phillips curve trade-off, but the central bank should not attempt to exploit it. There is no long-run Phillips curve trade-off (although Friedman tempered this position between 1968 and 1977 when he seemed to perceive the possibility of an upward-sloping long-run Phillips curve).

(5) Monetary policy is viewed as a process of determining the supply of money in circulation, and an optimal monetary policy involves minimizing the variability in the growth rate of some monetary aggregate.

(6) Money is any object that is used as a medium of exchange, and whether these objects are private or government liabilities is irrelevant for the analysis of monetary theory and policy.

We think it is also apparent that Friedman and his followers tended to be critical of contemporary central bank practices, and this tradition

\footnotetext{
${ }^{11}$ In the early 1980s a standard textbook put it this way: "As a result of all of this work quantity theorists and monetarists are no longer a despised sect among economists. While they are probably a minority, they are a powerful minority. Moreover, many of the points made by monetarists have been accepted, at least in attenuated form, into the mainstream Keynesian model. But even so, as will become apparent as we proceed, the quantity theory and the Keynesian theory have quite different policy implications" (Mayer, Duesenberry, and Aliber, 1981, emphasis added).
}

was carried on through such institutions as the Federal Reserve Bank of St. Louis and the Shadow Open Market Committee. One lasting influence of monetarism is the notion that low inflation should be a primary goal of policy, which is also a principle stressed by New Keynesian economists. However, the policy prescription in Friedman (1968) that central banks should adhere to strict targets for the growth of monetary aggregates is typically regarded as a practical failure. Old Monetarism tended to emphasize the long run over the short run: Money can be nonneutral in the short run, but exploitation of this by the central bank only makes matters worse (in part due to infamous long and variable lags). Policy should focus on long-run inflation. We also think it is fair to suggest that monetarists tended to favor relatively simple models, as compared to the Keynesian macroeconometric tradition.

Some but definitely not all of these ideas carry over to New Monetarism. Before moving to that, we mention that there are many other facets to the policy prescriptions, methodological ideas, and philosophical positions taken by Friedman and his epigones, any one of which may or may not fit with the thinking of any particular New Monetarist. In some sense Friedman's undeniable faith in free markets, for example, resembles the approach a mechanism design specialist might take, but in another sense it is the polar extreme, given the latter puts much weight on private information and other incentive problems. We do not want to get into all of these issues, but there is one position advocated by Friedman that we think is noteworthy, in the current climate, concerning fiscal rather than monetary policy. Friedman was clear when he argued that spending and tax proposals should be evaluated based on microeconomic costs and benefits, not on their potential impact on the macroeconomy. In stark contraposition, virtually all the popular and academic discussion of the recent stimulus package seems to focus on the size of multipliers, which to us seems misguided. But let us return to monetary economics, which is probably our (comparative) advantage. 


\subsection{New Monetarism}

Although dating such things precisely can be subtle, we would suggest that the foundations for New Monetarism can be traced to a conference on Models of Monetary Economies at the Federal Reserve Bank of Minneapolis in the late 1970s, with the proceedings and some post-conference contributions published in Kareken and Wallace (1980). Important antecedents are Samuelson (1958), which is a legitimate model of money in general equilibrium, and Lucas (1972), which sparked the rational expectations revolution and the move toward incorporating rigorous theory in macroeconomics. The Kareken and Wallace volume contains a diverse body of work with a common goal of moving the profession toward a deeper understanding of the role of money and the proper conduct of monetary policy, and spurred much research using overlapping generations and related models, including the one in Townsend (1980). ${ }^{12}$

Much of this work was conducted by Wallace and his collaborators during the 1980s. Some findings from that research are the following:

(1) Because Old Monetarists neglect key elements of economic theory, their prescriptions for policy can go dramatically wrong (Sargent and Wallace, 1982).

(2) The fiscal policy regime is critical for the effects of monetary policy (Sargent and Wallace, 1981, and Wallace, 1981).

(3) Monetary economics can make good use of received theory in other fields, like finance and public economics (Bryant and Wallace, 1979 and 1984).

A key principle, laid out first in the introduction to Kareken and Wallace (1980) and elaborated in Wallace (1998), is that progress can be made in monetary theory and policy analysis only by modeling monetary arrangements explicitly.

\footnotetext{
${ }^{12}$ In addition to much impressive modeling and formal analysis, the Kareken-Wallace volume also contains in some of the discussions and post-conference contributions a great deal of fascinating debate on methodology and philosophy of the sort that we would like to see resurface, related to our comments in the Introduction about healthy economic science.
}

In line with the arguments of Lucas (1976), to conduct a policy experiment in an economic model, it must be invariant to the experiment under consideration. One interpretation is the following: If we are considering experiments involving the operating characteristics of the economy under different monetary policy rules, we need a model in which economic agents hold money not because it enters utility or production functions, in a reduced-form fashion, but because money ameliorates some fundamental frictions in the exchange process. This is our last, best, and only hope for invariance, and it is why we are so interested in trying to carefully model frictions, instead of simply assuming some particular channel by which money matters. Of course, the suggestion that monetary economists need to look frictions in the face goes way back to Hicks (1935). ${ }^{13}$

There are various ways to try to conceptualize the notion of frictions. Just as Old Monetarists tended to favor simplicity, so do we. One reason for the preference for simple models is that, relative to Keynesian economics, there may be more of a focus on long-run issues such as the cost of steady state inflation, instead of business cycles. This is mainly because the long run is taken to be more important from a welfare perspective, but as a by-product, it often allows one to employ simpler models. It is also relevant to point out that tractability is especially important in monetary economics, where questions of existence, uniqueness versus multiplicity, and dynamics are big issues that can more easily and more naturally be addressed using analytic rather than numerical methods. With all due respect to computational economics, which has made brilliant advances in recent years, we believe that there are still some important questions to which the answer is not a number.

Overlapping generations models can be simple, although one can also complicate them as much as one likes, but much research in monetary theory following Kiyotaki and Wright (1989) instead uses matching models, building more on

\footnotetext{
${ }^{13}$ Notice that, in line with the previous discussion, we are talking about frictions in the exchange process, as opposed to frictions in the price-setting process, like nominal rigidities, where money does not help (in fact, it is really the cause of the problem).
} 
ideas in search and game theory than general equilibrium theory. ${ }^{14}$ Matching models are very tractable for many applications, although a key insight that eventually arose from this research program is that spatial separation per se is not the critical friction making money essential, where here we are using the term in a technical sense usually attributed to Hahn (1973): Money is essential when the set of allocations that can be supported (satisfying resource and incentive conditions) with money is bigger or better than without money. As pointed out by Kocherlakota (1998), and emphasized by Wallace (2001), with credit due to earlier work by Ostroy (see Ostroy and Starr, 1990) and Townsend (1987 and 1989), money is essential when it overcomes a double coincidence of wants problem combined with limited commitment and imperfect record keeping. Perfect record keeping, what Kocherlakota calls perfect memory, implies that efficient allocations can be supported through insurance and credit arrangements, or various other arrangements, in a large class of environments including those used by search theorists without the use of money.

It needs to be emphasized that random bilateral matching among a large number of agents can be a convenient way to generate a double coincidence problem and to motivate incomplete record keeping, but it is not otherwise important to the approach. Corbae, Temzelides, and Wright (2003) and Julien, Kennes, and King (2008), e.g., redo much of the early monetary search theory using directed rather than random matching, and although some of the results change, in interesting ways, the essence of the theory emerges unscathed. Moreover, although it is good, perhaps essential, for monetary economists to understand what may or may not make currency essential in the exchange process, New Monetarists are interested in a host of other issues, institutions, and phenomena. Developments in intermediation and payment

\footnotetext{
${ }^{14}$ Other papers in this literature will be discussed below, although a more comprehensive survey is to be found in Williamson and Wright (2010). See Ostroy and Starr (1990) for a survey of earlier attempts at building microfoundations for money using general equilibrium theory. Overlapping generations models are discussed and surveyed in various places, including Wallace (1980) and Brock (1990).
}

theories over the last 25 years are critical to our understanding of credit and banking arrangements, and one significant difference between Old and New Monetarists is how they think about the role of financial intermediaries and their interactions with central banks, as we discuss more formally in Section 6.

The 1980s saw important developments in the field, spurred by earlier progress in information theory. One influential contribution is Diamond and Dybvig (1983), which we now understand to be a useful approach to studying banking as liquidity transformation and insurance (although whether it can produce anything resembling a bank run depends on auxiliary assumptions, as discussed, e.g., by Ennis and Keister, 2009a,b). Other work involved well-diversified intermediaries economizing on monitoring costs, including Diamond (1984) and Williamson (1986), in models where financial intermediation is an endogenous phenomenon. The resulting intermediaries are well-diversified, process information in some manner, and transform assets in terms of liquidity, maturity, or other characteristics. The theory has also been useful in helping us understand the potential for instability in the banking and financial system (Ennis and Keister, 2009a,b) and how the structure of intermediation and financial contracting can propagate aggregate shocks (Williamson, 1987a, and Bernanke and Gertler, 1989).

A relatively new sub-branch of the area examines the economics of payments. This involves the study of payment and clearing systems, particularly among financial institutions, such as Fedwire in the United States, where central banks can play an important role (see Freeman, 1996, for an early contribution and Nosal and Rocheteau, 2009 , for a recent survey). The key insights from this literature are related to the role played by outside money and central bank credit in the clearing and settlement of debt, and the potential for systemic risk as a result of intraday credit. Even while payment systems are working well, work in this field is important, because the cost of failure is potentially great given the amount of money processed through such systems each day. New Monetarist economics not only has something to 
say about these issues, it is basically the only approach that could. How can one hope to understand payments and settlement without modeling the exchange process?

In an even newer research area, people have recently been using models consistent with our approach to study asset markets, including Duffie, Gârleanu, and Pederson (2005 and 2007), Vayanos and Weill (2008), and Lagos and Rocheteau (2009). This may come as a surprise to some people-it initially did to us-who might think financial markets are as close to a frictionless ideal as there is, but it turns out to be one of the most natural applications of search and bargaining theory. As Duffie, Gârleanu, and Pederson (2007) put it,

many assets, such as mortgage-backed securities, corporate bonds, government bonds, U.S. federal funds, emerging-market debt, bank loans, swaps and many other derivatives, private equity, and real estate, are traded in overthe-counter (OTC) markets. Traders in these markets search for counterparties, incurring opportunity or other costs. When counterparties meet, their bilateral relationship is strategic; prices are set through a bargaining process that reflects each investor's alternatives to immediate trade.

This branch of finance uses formal models very close to those presented below (see Williamson and Wright, forthcoming, for more discussion).

In terms of how we go about it, to reiterate what was said in the introduction, New Monetarists more or less try to abide by the following principles:

(1) Useful analysis in macro and monetary economics, including policy analysis, requires sound micro economic theory, which involves using what we know from general equilibrium, search, and game theory.

(2) Especially important is a clear and internally consistent description of the exchange process and the means by which money and related institutions help facilitate that process, implying that the theory must be built on environments with explicit frictions.
(3) Rigorous models of financial intermediation are important for monetary theory and policy: Credit, banking, and payment systems matter.

(4) Other things being equal relatively simple models are preferred. While this is true in most of economics, it is especially important in monetary theory, because existence, uniqueness versus multiplicity, and dynamics are big issues that are not easy to study numerically. This makes it crucial to come up with assumptions that deliver tractability without sacrificing too much along other dimensions.

(5) While no one theory can answer all questions, in monetary economics, there are important characteristics that we feel any good model should have. In addition to tractability, this includes the right amount of abstraction, and internal consistency (which means there are not too many institutions, like incomplete markets, nominal contracting, and so on, that are taken as primitives). It would be useful to have a benchmark model with these properties that is also flexible enough to address a variety of questions.

Taking the above as our desiderata, we now present a baseline New Monetarist model and show how it can be used to study several substantive issues. Since we go into detail concerning the technical aspects of related models in Williamson and Wright (forthcoming), here we provide only a cursory discussion of those before getting to the structure that we actually put to use.

\section{A BENCHMARK FRAMEWORK}

\subsection{Background}

The simplest setup consistent with the spirit of New Monetarist Economics is a version of firstgeneration monetary search theory along the lines of Kiyotaki and Wright (1993), which is a strippeddown version of Kiyotaki and Wright (1989 and 1991). In such a model, agents meet bilaterally and at random, which makes barter difficult due 
to a double-coincidence problem generated by specialization. Also, these models have limited commitment and imperfect memory, which makes credit arrangements difficult. Money is then essential in the sense that (the set of) equilibrium outcomes can be better with money than without it. We think this is a good starting point for monetary economics, since money is playing a bona fide role in facilitating exchange. Moreover, frictions like those in the models, or at least informal descriptions thereof, have long been thought to be important for understanding the role of money, by such luminaries as Jevons (1875), Menger (1892), and Wicksell (1967), among others. The goal of the early search-based literature is to formalize these ideas, to see which are valid under what assumptions, and to develop new insights.

These first-generation models make some strong assumptions, however, including the indivisibility of money and goods. This allows one to focus on describing the pattern of trade without having to determine the terms of trade, but does not otherwise seem especially desirable. Even with such assumptions in place, we think the theory captures something salient about money. One can look at Williamson and Wright (forthcoming) for a summary of results from these rudimentary models, but we can at least mention here the following. Equilibria exist where an intrinsically useless asset, fiat currency, is valued. These equilibria can have good welfare properties relative to pure barter, even if they typically do not achieve first best. They are tenuous in the sense that there coexist nonmonetary equilibria, although monetary equilibria are also robust in that they can survive even if we endow currency with some undesirable properties by giving it, say, a storage or transaction cost, or if we tax it. Money encourages specialization in the models, as has been understood since Adam Smith, but has not been previously easy to formalize. One can also use the model to analyze commodity money, international currency, some issues related to banking, and so on (see our companion paper, Williamson and Wright (forthcoming) for references).

Beginning the next generation of papers in this literature, Shi (1995) and Trejos and Wright (1995) endogenize prices by retaining the assump- tion that money is indivisible but allowing divisible goods and having agents bargain. Results stemming from these models illustrate additional properties of fiat and commodity money systems, and one can use the framework to study many substantive issues. Compared to the previous work, a new insight from these second-generation models is that the equilibrium price level is typically not efficient: Under natural assumptions, it can be shown that one does not get enough for one's money. Many other results and applications are available, and again, one can look at Williamson and Wright (forthcoming) for more discussion and references. But clearly, while this is an improvement over models where prices are not determined endogenously, and while research using the framework has proved productive, the maintained indivisibility of money makes the model ill suited for much empirical and policy analysis as it is usually conceived by practitioners.

When one admits divisible money, however, one has to keep track of the distribution of money across agents as a state variable, and this gets complicated, even using numerical methods. ${ }^{15}$ Still, Molico (2006) computes equilibria in his divisiblemoney model, and uses it to discuss the effects of inflation generated by transfers from the monetary authority. See also Chiu and Molico (2008 and 2010) and Dressler (2009 and 2010). Since we are interested in analytic results, we do not pursue the computational approach here. Instead we focus on models that allow us to avoid having to track distributions, and to this end there are two main routes. ${ }^{16}$ The first, originating with Shi (1997), gets a degenerate distribution from the assumption of large households (a natural exten-

\footnotetext{
${ }^{15}$ The problem is in dealing with the distribution of money, and wealth, more broadly defined, in multiple-asset models. Heterogeneousagent, incomplete-markets, macro models of the sort analyzed by Huggett (1993) or Krusell and Smith (1998) also have an endogenous distribution as a state variable, but the agents in those models do not care about this distribution per se-they only care about prices. Of course prices depend on the distribution, but one can typically characterize accurately prices as functions of a small number of moments. In a search model, agents care about the distribution of money directly, since they are trading with each other and not merely against their budget equations.

${ }^{16}$ Alternative approaches include Camera and Corbae (1999), Zhu (2003 and 2005), and a body of work emanating from the model introduced by Green and Zhou (1998), citations to which can be found in Jean, Stanislav, and Wright (2010).
} 
sion for random-matching models of the workershopper pair discussed in the cash-in-advance literature since Lucas, 1980b). Thus, each decisionmaking unit consists of many members, who search randomly, but at the end of each trading round they return to the homestead where they share any money they bring back. Loosely speaking, by the law of large numbers, large families start each new trading round with the same amount of money. See Shi (2006) for a discussion and survey of this approach.

We take another route, following Lagos and Wright (2005), where alternating centralized and decentralized markets take the place of families. This allows us to address a variety of issues in addition to rendering distributions tractable. And it helps reduce the gap between monetary theory with some claim to microfoundations and mainstream macro as, while money is essential in the decentralized markets, having some centralized markets allows us to add elements that are hard to integrate into pure search models, such as standard capital and labor markets, fiscal policy. For what it's worth, we also believe the framework provides a realistic way to think about economic activity. In actual economies some activity is relatively centralized-it is fairly easy to trade, credit is available, we take prices as given, etc.- - which is arguably well approximated by the apotheosis of a competitive market. But there is also much activity that is decentralized-it is not so easy to find a partner, it can be hard to get credit, etc.as in search theory. For all these reasons we like the approach.

\subsection{The Environment}

The population consists of a continuum of infinitely lived agents with unit mass, each of whom has discount factor $\beta$. We divide each period in discrete time into two subperiods. In one, agents interact in a decentralized market, or $\mathrm{DM}$, where there is pairwise random matching with $\alpha$ denoting the arrival rate (the probability of a match). Conditional on meeting someone, due to specialization (see Williamson and Wright, forthcoming, for more discussion), each agent has probability $\sigma$ of being able to produce something the other agent wants to consume but not vice versa, and the same probability $\sigma$ of wanting to consume what the other one can produce but not vice versa. Each of these two types of meetings involves a single coincidence of wants. Purely for simplicity, and without loss of generality, we assume no double-coincidence meetings, so that with probability $1-2 \sigma$ there is no opportunity for trade in a meeting. Also, there is no record keeping in the DM, in the sense that the agents cannot observe actions in meetings other than their own, and have no knowledge of the histories of their would-be trading partners in any given meeting.

In the other subperiod, agents interact in a frictionless centralized market, or CM, as in standard general equilibrium theory. In the CM there is also limited record keeping, in the sense that agents only observe prices, which is all they need to respect their budget constraints. In particular they do not observe the actions of other individuals directly, only market outcomes (prices), which makes it difficult to use game-theoretic triggers that might otherwise render money inessential (Aliprantis, Camera, and Puzzello, 2006 and 2007, and Araujo et al., 2010). Some applications do allow partial record keeping, so that, for example, bonds can be traded across two meetings of the $\mathrm{CM}$, although usually this is not crucial. Sometimes the setup is described by saying the DM convenes during the day and the CM at night, or vice versa, but this is not important for anything except perhaps mnemonics, to keep track of the timing. One can also proceed differently, without changing basic results, say as in Williamson (2007), where both markets are always open and agents randomly transit between them. ${ }^{17}$

There is one consumption good $x$ in the DM and another $X$ in the CM, although it is easy to have $x$ come in many varieties, or to interpret $X$

\footnotetext{
${ }^{17}$ For some issues it is also interesting to have more than one round of trade in the DM between meetings of the CM, as in Berentsen, Camera, and Waller (2005) or Ennis (2009), or more than one period of CM trade between meetings of the DM, as in Telyukova and Wright (2008). Chiu and Molico (2006) allow agents to transit between markets whenever they like, at a cost, embedding what looks like the model of Baumol (1952) and Tobin (1956) into general equilibrium, where money is essential, but that requires numerical methods.
} 
as a vector. For now $x$ and $X$ are produced onefor-one using labor $h$ and $H$, so the real wage in the $\mathrm{CM}$ is $w=1$. Preferences in any period encompassing one DM and CM are described by a standard utility function $\mathcal{U}(x, h, X, H)$. What is important for tractability, if not for the theory, in general, is quasilinearity: $\mathcal{U}$ should be linear in either $X$ or $H .{ }^{18}$ For now, we assume $\mathcal{U}$ is linear in $H$, and in fact we also make it separable,

$$
\mathcal{U}=u(x)-c(h)+U(X)-H .
$$

Assume $u^{\prime}>0, u^{\prime \prime}<0, u^{\prime}(0)=\infty, c^{\prime}>0, c^{\prime \prime} \geq 0$, $c^{\prime}(0)=u(0)=c(0)=0, U^{\prime}>0$, and $U^{\prime \prime} \leq 0$. Also, denote the efficient quantities by $x^{*}$ and $X^{*}$, where $u^{\prime}\left(x^{*}\right)=c^{\prime}\left(x^{*}\right)$ and $U^{\prime}\left(X^{*}\right)=1$ (we leave it as an exercise to verify these are efficient).

If we shut down the CM then this environment, including the random matching specification, technology, and preferences, is identical to that used by Molico (2006) in the model discussed above. And since the Molico (2006) model collapses to the one in Shi (1995) or Trejos and Wright (1995) when we make money indivisible, and to the one in Kiyotaki and Wright (1993) when we additionally make goods indivisible, these ostensibly different environments are actually special cases of one framework. As we discuss in Williamson and Wright (forthcoming), this is good not because we want one all-purpose vehicle for every issue in monetary economics, but because we want to avoid the impression that New Monetarist economics consists of a huge set of mutually inconsistent models. The same fundamental building blocks are used in the models discussed above, in the extensions presented below, in our companion paper, and in many other places in the literature, even if some applications sometimes make certain special assumptions.

Let $V_{t}(m)$ and $W_{t}(m)$ denote, respectively, the value function at date $t$ for an agent holding money balances $m$ at the beginning of the DM and the CM. Then we have

\footnotetext{
18 To be clear, one can proceed with general preferences, but this requires numerical methods; with quasilinearity, we can derive many results analytically. Actually, one can use general utility and still be achieve tractability if we assume indivisible labor, since then agents act as if utility is quasilinear (see Rocheteau et al., 2008).
}

$$
\begin{aligned}
W_{t}(m) & =\max _{X, H, \hat{m}}\left\{U(X)-H+\beta V_{t+1}(\hat{m})\right\} \\
\text { st } X & =H+\phi_{t}(m-\hat{m})+T,
\end{aligned}
$$

where $\phi_{t}$ is the CM value of money, or the inverse of the nominal price level $p_{t}=1 / \phi_{t}$, and $T$ is a lump-sum transfer, as discussed below. Assuming an interior solution (see Lagos and Wright, 2005), we can eliminate $H$ and write

$$
\begin{aligned}
& W_{t}(m)=\varphi_{t} m+T+\max _{X}\{U(X)-X\} \\
& +\max _{\hat{m}}\left\{-\varphi_{t} \hat{m}+\beta V_{t+1}(\hat{m})\right\} .
\end{aligned}
$$

From this it is immediate that $W_{t}(m)$ is linear with slope $\phi_{t} ; X=X^{*}$; and $\hat{m}$ is independent of wealth $\phi_{t} m+T$. This last result implies a degenerate distribution across agents leaving the CM: They all choose $\hat{m}=M$ regardless of the $m$ they brought in. ${ }^{19}$

In a sense, one can think of the CM as a settlement subperiod, where agents reset their liquidity positions. Quasilinearity implies they all rebalance to the same $\hat{m}$, leading to a representative agent in the DM. Without this feature the analysis is more complicated. It can also be more interesting, for some applications, but we want a tractable benchmark. By analogy, while models with heterogeneous agents and incomplete markets in macro generally are interesting, it is nice to have the basic neoclassical growth theory, with complete markets and homogeneous agents, as the textbook case. Since serious monetary theory with complete markets and homogeneity is a non-starter, we present this model as our benchmark, but one is free to relax our assumptions and use computational methods (analogous, perhaps, to the way some people compute large-scale overlapping generations models while others prove theorems in simpler versions).

To see one manifestation of this tractability, compared to many other models, consider an individual contemplating bringing $m$ dollars into the DM. Since we just established everyone else in the DM has $M$, it does not matter who the agent

\footnotetext{
${ }^{19}$ This is obvious at least if $V_{t}$ is strictly concave, which is the case under some conditions (given below), but as shown in Wright (2010), it is true generically even if $V_{t}$ is not strictly concave.
} 
under consideration meets, except insofar as it can determine whether he is a buyer or seller (all sellers look the same to a buyer and vice versa). Hence,

(2)

$$
\begin{aligned}
& V_{t}(m)=W_{t}(m)+\alpha \sigma\left\{u\left[x_{t}(m, M)\right]-\phi_{t} d_{t}(m, M)\right\} \\
& +\alpha \sigma\left\{-C\left[x_{t}(M, m)\right]+\phi_{t} d_{t}(M, m)\right\},
\end{aligned}
$$

where $x_{t}(m, M)$ is the quantity of goods and $d_{t}(m, M)$ the dollars traded at $t$ in a singlecoincidence meeting where the buyer has $m$ and the seller has $M$ (which, if you are following along, explains why the arguments are reversed in the second and third terms). Note that we used the earlier result $W_{t}^{\prime}(m)=\phi_{t}$ to simplify this.

The next step is to determine $x_{t}(\cdot)$ and $d_{t}(\cdot)$, and for now we use the generalized Nash bargaining solution (but see Section 4.1). Letting the bargaining power of the buyer be given by $\theta$ and the threat points by continuation values, $x_{t}(m, M)$ and $d_{t}(m, M)$ solve

$$
\max _{x, d}\left[u(x)-\varphi_{t} d\right]^{\theta}\left[-c(x)+\varphi_{t} d\right]^{1-\theta} \text { st } d \leq m .
$$

Again we used $W_{t}^{\prime}=\phi_{t}$, which makes this bargaining problem nice and easy. First note that in any equilibrium the constraint $d \leq m$ must bind (see Lagos and Wright, 2005). Then inserting $d=m$, taking the first-order condition (FOC) with respect to $x$, and rearranging, we get $\phi_{t} m=g(x)$ where

$$
g(x) \equiv \frac{\theta c(x) u^{\prime}(x)+(1-\theta) u(x) c^{\prime}(x)}{\theta u^{\prime}(x)+(1-\theta) c^{\prime}(x)} .
$$

This expression may look nasty, but $g(\cdot)$ is quite well behaved, and it simplifies a lot in some special cases; for example, $\theta=1$ implies $g(x)=c(x)$, in which case real balances paid to the producer $\phi_{t} m$ exactly compensate him for his cost. In any case, $\partial x / \partial m=\phi_{t} / g^{\prime}(x)>0$.

We have shown that for any $(m, \tilde{m})$, in equilibrium $d_{t}(m, \tilde{m})=m$ and $x_{t}(m, \tilde{m})$ depend on $m$ but not $\tilde{m}$. We can now differentiate (2) to obtain

$$
V_{t}^{\prime}(m)=(1-\alpha \sigma) \varphi_{t}+\alpha \sigma \varphi_{t} u^{\prime}\left(x_{t}\right) / g^{\prime}\left(x_{t}\right),
$$

where on the right-hand side $x_{t}=x_{t}(m)$. The marginal benefit of money in the DM is the marginal value of carrying it into the CM, which is $\phi_{t}$, with probability $1-\alpha \sigma$, plus the marginal value of spending it, which is $u^{\prime}(x) \partial x / \partial m$, with probability $\alpha \sigma$. Updating this one period and combining it with the FOC from the CM, $\phi_{t}=\beta V_{t+1}^{\prime}(\hat{m})$, we arrive at

(5) $\varphi_{t}=\beta \varphi_{t+1}\left[1+\ell\left(x_{t+1}\right)\right]$,

where we define

(6) $\ell(x) \equiv \alpha \sigma\left[\frac{u^{\prime}(x)}{g^{\prime}(x)}-1\right]$.

The expression in (6) is the liquidity premium, giving the marginal value of spending a dollar, as opposed to carrying it forward, times the probability $\alpha \sigma$ one spends it.

Assume for now that the lump-sum transfer $T$ is financed by printing currency, or, if negative, by retiring currency. Then the amount of currency in the $\mathrm{CM}$ at $t$ is the amount brought in by private agents $M_{t}$, plus the transfer $\mu_{t} M_{t}$, where $\mu_{t}$ is the rate of increase in the money stock. Market clearing implies $\hat{m}_{t}=(1+\mu) M_{t}=M_{t+1}$ is brought out of the CM and into the DM at $t+1$. Thus, the bargaining solution tells us $\phi_{t+t} M_{t+1}=g\left(x_{t+1}\right)$ for all $t$, and inserting this into (5) we arrive at

(7) $\frac{g\left(x_{t}\right)}{M_{t}}=\beta \frac{g\left(x_{t+1}\right)}{M_{t+1}}\left[1+\ell\left(x_{t+1}\right)\right]$.

For a given path of $M_{t}$, equilibrium can be defined as a list including paths for $V_{t}(\cdot), W_{t}(\cdot), x_{t}(\cdot)$, and so on, satisfying the relevant conditions. But (7) reduces all of this to a simple difference equation determining a path for $x_{t}$. Here we focus on stationary equilibria, where $x_{t}$ and hence $\phi_{t} M_{t}$ are constant, which makes sense as long as $\mu_{t}$ is constant (nonstationary equilibria, including sunspot, cyclic, and chaotic equilibria, are discussed in Lagos and Wright, 2003). In a stationary equilibrium, (7) simplifies nicely to $1+\mu=\beta[1+\ell(x)]{ }^{20}$

\footnotetext{
${ }^{20}$ One has to also consider the consolidated government budget constraint, say $G+T=(\mu-1) \phi M$, where $G$ is government CM consumption. But notice that it does not actually matter for (7) whether changes in $M$ are offset by changing $T$ or $G$-individuals would prefer lower taxes, other things equal, but this does not affect their decisions about real balances or consumption in the model. Therefore, we do not have to give new money away as a transfer, but can instead have the government spend it, for the purpose of describing the most interesting variables in equilibrium.
} 


\subsection{Result}

Having defined monetary equilibrium, we proceed to discuss some of its properties. To facilitate comparison to the literature, imagine that we can use standard methods to price real and nominal bonds between any two meetings of the CM, assuming these bonds are illiquid-they cannot be traded in the DM. ${ }^{21}$ Then the real and nominal interest rates $r$ and $i$ satisfy $1+r=1 / \beta$ and $1+i=(1+\mu)(1+r)$, the latter being of course the standard Fisher equation. Then we can rewrite the condition $1+\mu=\beta[1+\ell(x)]$ for stationary equilibrium derived above as

\section{(8) $\ell(x)=i$.}

Intuitively, (8) equates the marginal benefit of liquidity to its cost, given by the nominal interest rate $i$. In what follows we assume $i>0$, although we do consider the limit $i \rightarrow 0$ (it is not possible to have $i<0$ in equilibrium).

For simplicity let us assume $\ell^{\prime}(x)<0$, in which case there is a unique stationary monetary equilibrium and it is given by the $x>0$ that solves (8). It is not true that we can show $\ell^{\prime}(x)<0$ under the usual concavity and monotonicity assumptions, but there are conditions that work. One such condition is $\theta \approx 1$; another is that $c(x)$ is linear and $u(x)$ displays decreasing absolute risk aversion. Note also that the same conditions that make $\ell^{\prime}(x)<0$ make $V(m)$ strictly concave. In any case, this is not especially important, since the argument in Wright (2010) shows that there generically exists a unique stationary monetary equilibrium even if $\ell(x)$ is not monotone.

In terms of welfare and policy implications, the first observation is that it is equivalent for policymakers to target either the money growth or inflation rate, since both equal $\mu-1$; or they can target the nominal rate $i$, which is tied to $\mu$ through the Fisher equation. Second, it is clear that the initial stock of money $M_{0}$ is irrelevant for the real allocation (money is neutral), but the same is not true for the growth rate $\mu$ (money is

${ }^{21}$ Do not get confused: We are not introducing tangible objects called bonds here; we are considering a thought experiment where we ask agents what return they would require to move one unit of either $X$ or $m$ from the CM at $t$ to the CM at $t+1$. not superneutral). These properties are shared by many theories, of course. Next, it is easy to see that $\partial x / \partial i<0$, intuitively, because $i$ is a tax on DM activity. Since CM output $X=X^{*}$ is independent of $i$ in this basic setup, total output is also decreasing in $i$. However, it is important to point out that $X$ is not generally independent of $i$ if we allow nonseparable utility (see Williamson and Wright, forthcoming).

One can also show that $x$ is increasing in bargaining power $\theta$, that $x<x^{*}$ for all $i>0$, and in fact, $x=x^{*}$ iff $i=0$ and $\theta=1$. The condition $i=0$ is the Friedman rule, which is standard, while $\theta=1$ is a version of the Hosios (1990) condition describing how to split the surplus in a socially efficient fashion in bilateral trade, which does not show up in reduced-form monetary theory. To understand it, note that in general there is a holdup problem in money demand analogous to the usual problem with ex ante investments and ex post negotiations. Thus, agents make an investment when they acquire cash in the CM, which pays off in single-coincidence meetings since it allows them to trade. But if $\theta<1$, producers capture some of the gains from trade, leading agents to initially underinvest in $\hat{m}$. The Hosios condition tells us that investment is efficient when the payoff to the investor is commensurate with his contribution to the total surplus, which in this case means $\theta=1$, since it is the money of the buyer (and not that of the seller) that allows the pair to trade.

There is reason to think that this is important in terms of quantitative and policy analysis, and not merely a technical detail. To make the case, first consider the typical quantitative exercise using something like a cash-in-advance model, without other explicit frictions, where one asks about the welfare cost of fully anticipated inflation. If as usual we measure this cost by asking agents what fraction of consumption they would be willing give up to go from, say, 10 percent inflation to the Friedman rule, the answer is generally very low. There are many such studies, but we can summarize the typical result by saying that consumers would be willing to give up around $1 / 2$ of 1 percent, or perhaps slightly more, but not above 1 percent, of their consumption 
(see Cooley and Hansen, 1989, or Lucas, 2000, for representative examples, or Craig and Rocheteau, 2008, for a survey). This has led many economists to conclude that the inflation tax distortion is not large, and may be one reason that New Keynesians focus virtually all their attention on sticky-price distortions.

Given the apparent aversion to inflation of many politicians, as well as regular people, one may wonder, why are the numbers generated by those models so small? The answer is straightforward. In standard cash-in-advance and other reduced-form models, at the Friedman rule we get the first best. Hence, by the envelope theorem, the derivative of welfare with respect to $i$ is 0 at the Friedman rule, and a small inflation matters little. This is consistent with what one finds in our benchmark model when we set $\theta=1$. But if $\theta<1$, then the envelope theorem does not apply, since while $i=0$ is still optimal it is a corner solution, given $i<0$ is not feasible. Hence, the derivative of welfare is not 0 at $i=0$, and a small deviation from $i=0$ has a first-order effect. The exact magnitude of the effect of course depends on parameter values, but in calibrated versions of the model it can be considerably bigger than what one finds in the reduced-form literature. These results lead New Monetarists to rethink the previously conventional wisdom that anticipated inflation does not matter much.

One should look at the individual studies for details, but we can sketch the method. Assume $U(X)=\log (X), u(x)=A x^{1-a} /(1-a)$, and $c(x)=x$. Then calibrate the parameters as follows. First set $\beta=1 /(1+r)$, where $r$ is some average real interest rate in the data. In terms of arrival rates, we can at best identify $\alpha \sigma$, so normalize $\alpha=1$. In fact, it is not that easy to identify $\alpha \sigma$, so for simplicity set $\sigma$ to its maximum value of $\sigma=1 / 2$, although this is actually not very important for the results. We need to set bargaining power $\theta$, as discussed below. Then, as in virtually all other quantitative monetary models, we set the remaining parameters $A$ and $a$ to match the so-called money demand observations. By these observations we mean the empirical relationship between $i$ and the inverse of velocity, $M / P Y$, which is traditionally interpreted as money demand by imagining agents setting real balances proportional to income, with a factor of proportionality that depends on the opportunity cost $i$.

Here, with $U(X)=\log (X)$, real CM output is $X^{*}=1$ (a normalization), and so nominal CM output is $P X=1 / \phi$. Nominal DM output is $\alpha \sigma M$, since in every single-coincidence meeting $M$ dollars change hands. Hence, total nominal output is $P Y=1 / \phi+\alpha \sigma M$. Using $\phi M=g(x)$, we get

(9) $\frac{M}{P Y}=\frac{g(x)}{1+\alpha \sigma g(x)}$,

and since $x$ is decreasing in $i$, so is $M / P Y$. This is the money-demand curve implied by theory. Given $\theta, g(x)$ depends on preferences, and we can pick the parameters $a$ and $A$ of $u(x)$, by various methods, to fit (9) to the data (assuming, for simplicity, say, that each observation corresponds to a stationary equilibrium of the model, although one can also do something more sophisticated). To implement this one has to choose an empirical measure of $M$, which is typically $M 1 .^{22}$

This is all fairly straightforward, the only nonstandard parameter in quantifying the model being $\theta$, which does not show up in theories with price taking. A natural target for calibrating $\theta$ is the markup, price over marginal cost, since it seems intuitive that this should convey information about bargaining power. One can compute the average markup implied by the model and set $\theta$ so that this matches the data. In terms of which data, we think the evidence discussed by Faig and Jerez (2005) from the Annual Retail Trade Survey, describing markups across various types of retailers, is most relevant. According to these data, at the low end, in warehouse clubs, superstores, automotive dealers, and gas stations, markups range between 1.17 and 1.21; and at the high end, in specialty foods, clothing, footware, and furniture, they range between 1.42 and 1.44. Aruoba, Waller, and Wright (2009) target 1.3, at the midpoint of these data. Lagos and Wright

\footnotetext{
${ }^{22}$ Which measure of $M$ one uses does make a difference (as it would in any model of money, with or without microfoundations). One might think a more natural measure would be Mo based on a narrow interpretation of the theory, but this is probably taking the model too literally for empirical work (see, e.g., Lucas, 2000). More research is needed to better match theory and data on this dimension.
} 
(2005) earlier used 1.1, consistent with other macro applications (e.g., Basu and Fernald, 1997). However, in this range, the exact value of $\theta$ does not matter too much.

It is now routine to compute the cost of inflation. It is hard to summarize the final answer with one number, since the results can depend on factors such as the sample period, frequency (monthly, quarterly, or annual), whether one includes complications like capital or fiscal policy, and so on. However, it is safe to say that Lagos and Wright (2005) can get agents to willingly give up 5 percent of consumption to eliminate a 10 percent inflation, which is an order of magnitude bigger than previous findings. In a model with capital and taxation, Aruoba, Waller, and Wright (2009) get closer to 3 percent when they target a markup of 1.3, which is still quite large. There are many recent studies using variants of New Monetarist models that have come up with similar numbers (again, see Craig and Rocheteau, 2008). Two points to take away from this are the following: First, the intertemporal distortion induced by inflation may be more costly than many economists used to think. Second, getting into the details of monetary theory is not only a matter of striving for logical consistency or elegance; it can also make a big difference for quantitative and policy analysis.

Which distortions are most important? Although there is more work to be done on this question, state-of-the-art research by Aruoba and Schorfheide (2010) attempts to answer it by estimating a model integrating New Keynesian and New Monetarist features (and they provide references to related work). They compare the importance of the sticky-price friction, which implies 0 inflation is optimal, and the intertemporal inflation distortion on which we have been focusing, which recommends the Friedman rule. They consider four scenarios, having to do with whether they try to fit the short- or long-run money-demand elasticity, and on whether the terms of trade are determined in the DM according to Nash bargaining or Walrasian pricing (see Section 4.1). In the version with bargaining designed to match the short-run elasticity, despite a reasonably-sized sticky-price distortion, the Friedman rule turns out to be optimal after all. The other three versions yield optimal inflation rates of -1.5 percent, -1 percent, and -0.75 percent. Even considering parameter uncertainty, they never find optimal inflation close to 0 . They conclude that the two distortions are about equally important. Again, more work needs to be done, but in light of these findings, we see no compelling evidence supporting the New Keynesian assertion that one may with impunity ignore intertemporal inflation distortions, or monetary distortions, or money, more generally.

\section{EXTENSIONS}

In this section, we discuss some extensions in the literature to the benchmark New Monetarist model, before moving to new results.

\subsection{Alternative Mechanisms}

In the previous section we determined the terms of trade between buyers and sellers in the DM using the Nash bargaining solution. This seems reasonable in a bilateral matching context and is actually fairly general, at least in the sense that as we vary bargaining power $\theta$ between 0 and 1, we trace out the pairwise core (the set of bilaterally efficient trades). But alternative solution concepts can and have been used. Rocheteau and Wright (2005), among many others since, consider Walrasian price taking, as well as price posting with directed search, in the benchmark model. Aruoba, Rocheteau, and Waller (2007) consider bargaining solutions other than Nash. Galenianos and Kircher (2008) and Dutu, Julien, and King (2009), in versions with some multilateral meetings, use auctions. Ennis (2008), Dong and Jiang (2009), and Sanches and Williamson (2010a) study pricing with private information. $\mathrm{Hu}$, Kennan, and Wallace (2009) use pure mechanism design. Head et al. (2010) use price posting with random search.

While these may all be appropriate for particular applications, in the interests of space, here we present just one: Walrasian pricing. This can be motivated by interpreting agents as meeting in large groups in the DM, rather than bilaterally, and assuming that whether one is a buyer or 
seller is determined by preference and technology shocks rather than random matching. It might help to think about labor search models, like Mortensen and Pissarides (1994), which uses bargaining, and Lucas and Prescott (1974), which uses price taking. A standard interpretation of the latter is that workers and firms meet on islands representing local labor markets, but on each island there are enough workers and firms that it makes sense to take wages parametrically. The same is true in monetary models: Specialization and anonymity can lead to an essential role for money independent of whether agents meet in small or large groups.

Let $\gamma$ be the probability of being a buyer in any given DM subperiod, and also the probability of being a seller, so that we have the same measure of each, although this is easy to relax. ${ }^{23}$ Assume for now that whether an agent ends up a buyer or seller in the DM is realized after the CM closes. Hence, agents are homogeneous ex ante, and they all choose the same $\hat{m}$ (we consider ex ante heterogeneity below). Leaving off $t$ subscripts when there is little risk of confusion, the CM problem is the same as above, but in the DM

$$
V(m)=\gamma V^{b}(m)+\gamma V^{s}(m)+(1-2 \gamma) W(m),
$$

where $V^{b}(\cdot)$ and $V^{s}(\cdot)$ are the payoffs to ending up a buyer or a seller ex post. These payoffs are given by

$$
\begin{aligned}
& V^{b}(m)=\max \{u(x)+W(m-\tilde{p} x)\} \text { st } \tilde{p}_{X} \leq m \\
& V^{s}(m)=\max \{-c(x)+W(m+\tilde{p} x)\},
\end{aligned}
$$

where $\tilde{p}$ is the DM nominal price of $x$ (which in general differs from the CM price $p=1 / \phi$ ). The buyer's constraint always binds, $\tilde{p} x=m$, exactly as in the bargaining model. Then, market clearing in the DM and optimization imply that, to use Walrasian pricing, simply replace $g(x)$ with $c(x)$ and $\alpha \sigma$ with $\gamma$. In particular, the same simple condition $\ell(x)=i$ in (8) determines the unique stationary monetary equilibrium, as long as in the formula for $\ell(x)=\alpha \sigma\left[u^{\prime}(x) / g^{\prime}(x)-1\right]$ we replace

\footnotetext{
${ }^{23}$ We assume here that one can never be both a buyer and seller in the same subperiod, but this is also easy to relax, just like it is easy to allow some double-coincidence meetings in the matching model.
}

$\alpha \sigma$ with $\gamma$ and $g^{\prime}(x)$ with $c^{\prime}(x)$. The results are otherwise qualitatively the same. However, there can be very interesting quantitative differences between the Nash and Walrasian versions of the model (see Aruoba, Waller, and Wright, 2009, or Aruoba and Schorfheide, 2010, for a case in point). Also, notice that here we made two changes to the baseline model: We generate the double coincidence problem via preference and technology shocks, instead of random bilateral matching; and we swapped Nash bargaining for Walrasian pricing. One could of course use preference and technology shocks instead of matching and stick with bargaining, or one could impose price taking with bilateral matching, although this seems less reasonable.

\subsection{Ex Ante Heterogeneity}

Here we present a simple extension of the benchmark model to illustrate another application and to make some methodological points. As above, preference and technology shocks rather than matching generate the DM double coincidence problem, but now agents know the realization of these shocks before they choose $\hat{m}$ in the CM. In fact, in our quasilinear specification, it is equivalent to assume there are two permanently distinct types: buyers, who may consume but never produce in the DM; and sellers, who may produce but never consume in the DM. ${ }^{24}$ We can allow buyers and sellers to have different CM utility functions, say $U^{b}(X)-H$ and $U^{s}(X)-v H .^{25}$ Denote the measures of buyers and sellers by $n_{b}$ and $n_{s}$. If we normalize $n_{s}=1$, then by varying

\footnotetext{
${ }^{24}$ In case it is not obvious that it is equivalent to have permanently different types or types determined every period, it follows from the fact that agents exit each CM with a clean slate, rebalancing their money balances appropriately to wipe out previous histories. Notice also that it makes sense to have some agents who are permanently sellers in the DM only when the CM is operative-otherwise, say in Molico's model, what would they do with their money? Similarly it makes sense to have some agents who are permanently buyers in the DM only when the CM is operative-otherwise, where would they get their money?

${ }^{25}$ A case used in some applications is $U^{b}(X)=0, U^{s}(X)=X$, and $v=0$, which means buyers consume only in the DM and produce only in the CM, while sellers do just the opposite. Notice that $v=0$ implies we need $U s(X)$ to be linear if we want quasilinearity. In some applications, sellers are interpreted as firms operating in the DM, paying dividends to their owner in the CM (e.g., Berentsen, Menzio, and Wright, 2010).
} 
$n_{b}$ we allow variation in market tightness in the DM, given by $\tau=n_{b} / n_{s}$.

We now have to write separate value functions for buyers and sellers in the CM. Again, leaving off the $t$ subscripts, after eliminating $H$, these can be written

$$
\begin{aligned}
& W^{b}(m)=\varphi m+T+U^{b}\left(X^{b}\right)-X^{b} \\
& +\max _{\hat{m}}\left\{-\varphi \hat{m}+\beta V^{b}(\hat{m})\right\}
\end{aligned}
$$

$$
W^{s}(m)=\varphi m+T+U^{s}\left(X^{s}\right)-v X^{s}+\beta V^{s}(0),
$$

where we use two results that should be obvious: Buyers and sellers respectively choose $X^{b}$ and $X^{s}$, where $U^{j}\left(X^{j}\right) \leq 1$ with equality if $X^{j}>0$; and only buyers ever choose $\hat{m}>0$, so that $\hat{m}=0$ for sellers. Hence we no longer have a degenerate distribution of money balances in the DM, but this does not complicate the analysis. Indeed, it is perhaps worth emphasizing that what makes the framework easy to use is not degeneracy, per se, but history independence. It is the fact that the distribution of money in the DM is degenerate conditional on agent type that begets tractability.

In the DM,

(13) $V^{s}(0)=-k_{s}+W^{s}(0)+\alpha_{s} \sigma\{-c[x(\bar{m})]+\varphi \bar{m}\}$,

where we use Nash bargaining, implying the result $d=\hat{m}$ and $x=x(\hat{m})$, with $\hat{m}$ being the money the buyer chooses, while sellers take it as given that buyers have $\bar{m}$ (they are equal in equilibrium). Additionally, for buyers and sellers, respectively, we add flow search costs $k_{b}$ and $k_{s}$ and distinguish the arrival rates as $\alpha_{b}$ and $\alpha_{s}$, which can now be endogenous. Notice that even though we use the same notation, $V^{b}(\cdot)$ and $V^{s}(\cdot)$ are different here than in Section 4.1, where agents were homogeneous ex ante (when they choose $\hat{m}$ ). Manipulating the buyer's FOC $\phi=\beta V^{\prime}(\hat{m})$, following the same steps as in the benchmark model, we get the analogous equilibrium condition

(14) $i=\ell^{b}(x) \equiv \alpha_{b} \sigma\left[\frac{u^{\prime}(x)}{g^{\prime}(x)}-1\right]$.
This extension of the benchmark model is often adopted in applications, where it may be more natural, or easier. Here we can use it to expound on a venerable issue: the effect of inflation on the time it takes people to spend their money. Conventional wisdom has it that higher inflation makes people spend money faster-like a hot potato they want to get rid of sooner rather than later -and this is one channel via which inflation increases velocity. ${ }^{26}$ Search-based theory seems ideal for studying this phenomenon. Li (1994 and 1995) introduced endogenous search effort into a first-generation model, and proxied for inflation with taxation, since it is hard to have inflation with indivisible money. He shows that increasing his inflation-like tax makes buyers search harder and spend money faster, increasing velocity. Moreover, some inflation is good for welfare, because there is too little search under laissez faire, because agents do not internalize the effect of their search effort on others' expected payoffs.

Lagos and Rocheteau (2005) show, however, that the main result is an artifact of indivisibilities. They introduce search intensity into the standard New Monetarist framework, which allows them to model inflation directly, and more importantly to determine prices endogenously. They then prove that inflation reduces buyers' search effort, the opposite of Li's $(1994,1995)$ finding. Intui-

\footnotetext{
${ }^{26}$ Of Keynes's many beautiful passages, we like this one: “The public discover that it is the holders of notes who suffer taxation [from inflation]... and they begin to change their habits and to economize in their holding of notes. They can do this in various ways...[T]hey can reduce the amount of till-money and pocket-money that they keep and the average length of time for which they keep it, even at the cost of great personal inconvenience...By these means they can get along and do their business with an amount of notes having an aggregate real value substantially less than before. In Moscow the unwillingness to hold money except for the shortest possible time reached at one period a fantastic intensity. If a grocer sold a pound of cheese, he ran off with the rubles as fast as his legs could carry him to the Central Market to replenish his stocks by changing them into cheese again, lest they lost their value before he got there; thus justifying the prevision of economists in naming the phenomenon velocity of circulation! In Vienna, during the period of collapse...[it] became a seasonable witticism to allege that a prudent man at a cafe ordering a bock of beer should order a second bock at the same time, even at the expense of drinking it tepid, lest the price should rise meanwhile" (Keynes, 1924, p. 51).

We like it not only because it involves beer and cheese, consistent with our Wisconsin connections, but also because Keynes was able to anticipate the usefulness of our benchmark specification where agents periodically visit the Central(ized) Market.
} 
tively, people cannot avoid the inflation tax by spending money more quickly, buyers can only pass it on to sellers, who are not inclined to absorb it for free. When prices can adjust, inflation reduces $x$ and hence the trading surplus, which reduces the return to DM activity. Thus, agents invest less in this activity, which means search effort goes down, and they end up spending money more slowly. Li's ostensibly plausible finding fails when prices are endogenous-somewhat reminiscent of Gresham's law, that bad money drives out good money, which also holds when prices are fixed but not necessarily when they are flexible (see Friedman and Schwartz, 1963, for a discussion and Burdett, Trejos, and Wright, 2001, for a theoretical analysis). We would not claim this is a puzzle in any serious sense, but several people have worked on trying to resurrect the result that inflation makes people spend money faster in various extensions of the benchmark model, including Ennis (2009) and Nosal (2010).

One resolution is proposed by Lagos and Rocheteau (2005) themselves, who can get search effort to increase with inflation when they replace bargaining by price posting, although their result is not very robust-it only holds for some parameter values, and in particular for low inflation rates. Here we take a different tack, following Liu, Wang, and Wright (2010). We start with a very simple matching technology, which assumes that, as in Li (1995), sellers wait passively, while buyers actively search by directly choosing $\alpha_{b}$ at flow cost $k_{b}=k\left(\alpha_{b}\right)$. Simplicity comes from the fact that with this technology search effort by other buyers does not affect the arrival rate of an individual buyer, although it does affect the arrival rate of sellers (see Liu, Wang, and Wright, 2010, for details, but note that this is only used to ease the presentation). Taking the FOC with respect to $\alpha_{b}$ in (12) and using the bargaining solution $\phi m=g(x)$, we have

(15) $k^{\prime}\left(\alpha_{b}\right)=\sigma[u(x)-g(x)]$.

Equilibrium is a quantity $x$ and an arrival rate $\alpha_{b}$ solving (14) - (15). It is not hard to show, as in Liu, Wang, and Wright (2010), that in equilibrium $x$ and $\alpha_{b}$ both fall with $i$.
This is our simplified version of the Lagos and Rocheteau (2005) result that inflation makes buyers spend their money less quickly, because it reduces the expected gain from a meeting, $\sigma[u(x)-g(x)]$. As we said, one can try to overturn this by changing the pricing mechanism, but instead we change the notion of search intensity: Rather than the intensive margin (effort), we consider the extensive margin (participation). That is, we introduce a free entry decision by buyers, similar to the decision of firms in the textbook labor search model in Pissarides (2000) (for other applications, one may alternatively consider entry by sellers or allowing agents to choose whether to be buyers or sellers in the DM). For this demonstration, we use a general constant returns to scale matching technology. Thus, the number of DM meetings $n=n\left(n_{b}, n_{s}\right)$ depends on the measures of buyers $n_{b}$ and sellers $n_{s}$ in the market, and $\alpha_{b}=n\left(n_{b}, n_{s}\right) / n_{b}=n(\tau, 1)$, where $\tau=n_{b} / n_{b}$. We make the usual assumptions on $n(\cdot) .{ }^{27}$

We now set $k_{b}=0$, but assume buyers must pay a fixed cost $k$ to enter the DM, while sellers get in for free. Hence, all sellers participate and $n_{s}=1$, while $n_{b}$ is endogenous. Assuming some but not all buyers participate, they must be indifferent about going to the DM, which as a matter of algebra can be shown to imply

(16) $k+i g(x)=\alpha_{b} \sigma[u(x)-g(x)]$.

This equates the total cost of participating in the $\mathrm{DM}$, the entry cost $k$ plus the real cost of carrying cash $i \phi \hat{m}=i g(x)$, to the expected benefit. A monetary equilibrium in this model is a non-zero solution $\left(x, \alpha_{b}\right)$ to (14) and (16), from which we can easily get the rest of the endogenous variables, including the measure of participating buyers $n_{b}$, which is a decreasing function of $\alpha_{b}$. One can verify, as in Liu, Wang, and Wright (2010), that there is a unique equilibrium, with $x$ decreasing and $\alpha_{b}$ increasing with $i$.

Thus we unambiguously get the hot potato effect $\partial \alpha_{b} / \partial i>0$ that was elusive, at least with

\footnotetext{
${ }^{27}$ It is twice continuously differentiable, strictly increasing, and strictly concave. Also, $n\left(n_{b}, n_{s}\right) \leq \min \left(n_{b}, n_{s}\right), n\left(0, n_{s}\right)=n\left(n_{b}, 0\right)=0$, $\lim _{\tau \rightarrow \infty} \alpha_{b}=0$, and $\lim _{\tau \rightarrow \infty} \alpha_{b}=1$.
} 
bargaining, when search intensity was modeled on the intensive margin. The intuition is crystal clear: An increase in inflation has to lead to buyers spending their money faster, because this is the only way to keep them indifferent about participating! It works by having $n_{b}$ go down, naturally, when $i$ increases. Moreover, this implies velocity unambiguously increases with $i$. In terms of welfare, it can be shown that (as in the benchmark model), the Friedman rule $i=0$ plus the Hosios condition $\theta=1$ are necessary and sufficient for $x=x^{*}$ But this does not in general imply efficiency in terms of entry, because of so-called search externalities: With a general matching function, participation by buyers increases the arrival rate for sellers and decreases it for other buyers. There is a separate Hosios condition for efficient participation, which as in a standard Pissarides (2000) model equates $\theta$ to the elasticity of the matching function with respect to $n_{b}$. But this conflicts in general with the condition $\theta=1$ required for $x=x^{*}$. Further analyzing efficiency and policy interventions in this class of models is an important area of investigation (see, e.g., Berentsen and Waller, 2009).

There are at least two reasons to be interested in these issues. One is normative: Ongoing research is studying whether there is, apropos the previous paragraph, too little or too much search or entry under laissez faire, and what policy can do about it. The other is positive: The effect of inflation on the speed with which people spend money is one channel through which it affects velocity, which is related to money demand. This is interesting for many reasons, including, as we saw in Section 3, the fact that it helps calibrate the model and measure the cost of inflation. We also think this subsection makes the following methodological point. We are arguing generally for better foundations for monetary economics. Although it is not the only possible way to proceed, it is sometimes convenient and informative to use search-and-bargaining theory. We have often heard it said that everything that can be done with search and bargaining can also be done using a money-in-the-utility-function or cash-inadvance model. Therefore, as the argument goes, we do not need search and bargaining. This application is a manifest counterexample: The interesting issues are all about search and bargaining. ${ }^{28}$

\subsection{Other Extensions}

Williamson and Wright (forthcoming) provide more details and references, but it would not hurt here to briefly summarize a few existing applications and generalizations of the benchmark model. As already mentioned, various alternative pricing mechanisms have been considered. People have included neoclassical capital and labor markets, and versions that nest standard real business cycle theory as a special case. Others have studied labor markets and the Phillips curve, using either Rogerson (1988) or Mortensen and Pissarides (1994) models of unemployment. People have included unanticipated inflation and signal extraction problems to quantify the importance of monetary uncertainty, while others have introduced private information to study recognizability and the counterfeiting of money or other assets. Others have analyzed optimal fiscal and monetary policy. Some people have introduced banking in various ways, while others have studied technology transfer and economic growth. Still others have studied the interaction between money and bonds, details of monetary policy implementation, the use of credit cards, and various issues in finance. There are many other applications and extensions of the benchmark model, both theoretical and empirical. In the rest of this essay we will present some examples related to asset markets and to intermediation.

\section{ASSET PRICING AND LIQUIDITY}

New Monetarist models provide insights into the exchange process and allow us to be explicit about the frictions that provide a role for money. Another advantage is that they allow us to consider a rich array of assets, credit arrangements, and intermediary structures. In this section we construct a version with two assets: money and

\footnotetext{
${ }^{28}$ Berentsen, Menzio, and Wright (2010) provide a different argument pertaining to search-and-bargaining models and reduced-form models delivering different results, both qualitatively and quantitatively.
} 
equity shares. ${ }^{29}$ We use the setup with ex ante heterogeneity developed in Section 4.2, with no entry costs, so that all buyers and sellers participate in the DM, and here we normalize $n_{b}=1$. Again, in the DM, buyers always want to consume but cannot produce, while sellers are always able to produce but do not want to consume. As before, we can give buyers and sellers different CM utility $U^{b}(X)-H$ and $U^{s}(X)-A^{s} H$. Also, to reduce notation we set $c(x)=X$, and buyers in the DM now make take-it-or-leave-it offers $\theta=1$. Also, to make the discussion of welfare below more interesting, we assume it can be costly to maintain the stock of currency: It uses up $\omega \phi M$ units of the CM good $X$ to maintain a real currency supply of $\phi M$ where $M$ is the stock of currency before the transfer from the government occurs in the CM. This can be interpreted as the cost of replacing worn-out notes, or thwarting counterfeiters, perhaps, and is financed through lump-sum taxes in the CM.

As is standard, following Lucas (1978), there is a productive asset in this economy that one can think of as a tree in fixed supply, normalized to 1 , that yields a dividend $y$ in fruit in units of the numeraire each period in the CM. Agents can trade equity shares in the tree in the $\mathrm{CM}$ at price $\psi$. Ownership of $a$ shares entitles a shareholder to receive ay units of $X$ in the CM. In the DM, for simplicity, each buyer is matched with a seller with probability 1 . As in the benchmark model, there is no record keeping, so credit is unavailable. Also, because we want to have both money and equity used in transactions, even when money is dominated in rate of return, we give shares a disadvantage in terms of recognizability. Thus buyers in the DM can costlessly produce fake shares, which are illegitimate claims to dividends in the CM, perhaps because they are counterfeit-bad claims to good trees-or because they are lemonsgood claims to bad trees (see Lester, Postlewaite, and Wright, 2009 and 2010; Rocheteau, 2009; and $\mathrm{Li}$ and Rocheteau, 2010, for more on this).

\footnotetext{
29 The presentation here has some features in common with the multiple-asset models of Geromichalos, Licari, and Suarez-Lledo (2007), Lagos (2008), Lagos and Rocheteau (2008), and Lester, Postlewaite, and Wright (2010), as well as models of money and credit, such as Sanches and Williamson (2010b).
}

To capture the extent of the recognizability problem, following Williamson and Wright (1994), in a fraction $\eta$ of DM meetings the seller has no technology for discriminating between phony and genuine shares, so they do not accept them (if they did they would only receive fakes). We call these meetings nonmonitored. In these meetings, money, which can always be recognized, is the only object accepted in trade. In the remaining fraction $1-\eta$ of DM meetings, sellers can differentiate between genuine and phony shares, so equity as well as currency are potentially acceptable. We call these meetings monitored, with one idea being that the seller can keep a record of who gave him any particular asset, so that when he gets to the next frictionless CM, where phony and genuine shares can always be distinguished, he could report and we could punish severely anyone who passed a fake. This is not the only interpretation, however, another one being that the seller in a monitored meeting has a technology to verify an asset's authenticity.

The timing is such that buyers do not know whether they will be in a monitored or nonmonitored meeting in the DM until after the CM closes. Therefore, the problem for a buyer coming into the $\mathrm{CM}$ with a portfolio $(m, a)$ of currency and shares is given, after eliminating $H$, by

$$
\begin{aligned}
& W^{b}(m, a)=U^{b}\left(X^{b}\right)-X^{b}+\varphi m+(\psi+y) a \\
& +T+\max _{\hat{m}, \hat{a}}\left\{-\varphi \hat{m}-\psi \hat{a}+\beta V^{b}(\hat{m}, \hat{a})\right\},
\end{aligned}
$$

where $X^{b}$ satisfies $\partial U^{b}\left(X^{b}\right) / \partial X^{b} \leq 1$ with equality if $X^{b}>0 .{ }^{30}$ In any case, $\partial W^{b} / \partial m=\phi$ and $\partial W^{b} / \partial a$ $=\psi+y$. We do not actually need to consider the seller's problem beyond noting that, as long as we assume sellers' preferences are quasilinear, their CM value function will also satisfy $\partial W^{s} / \partial m$ $=\phi$ and $\partial W^{s} / \partial a=\psi+y$. Given this, in nonmonitored and monitored DM meetings the bargaining solutions with $\theta=1$ and $c(x)=x$ are $x^{N}=\phi d^{N}$ and $x^{M}=\phi d^{M}+e(\psi+y)$, where now $d^{N} \leq \hat{m}$ and $d^{M} \leq \hat{m}$ are dollars that change hands in nonmonitored and monitored trades, and $e \leq \hat{a}$ is

\footnotetext{
${ }^{30}$ In the special case mentioned above, where $U^{b}(X) \equiv 0$ and buyers consume only in the DM, $X^{b}=0$, but again this does not really matter for the interesting results.
} 
the amount of equity handed over in a monitored trade (as we said above, no equity changes hands in non-monitored trades).

We can anticipate $d^{N}=d^{M}=\hat{m}$, without loss of generality, but we cannot be sure of $e=\hat{a}$, because buyers never want to buy more than $x^{*}$. Let $a^{*}$ be the amount of equity required to buy $x^{*}$ in a monitored meeting, given the buyer also spends $\hat{m}$, defined by $x^{*}=\phi \hat{m}+a^{*}(\psi+y)$. Then $x^{M}=\phi m+\hat{a}(\psi+y)$ if $\hat{a}<a^{*}$ and $x^{M}=x^{*}$ otherwise, while $e=\hat{a}$ if $\hat{a}<a^{*}$ and $e=a^{*}$ otherwise. The DM value function for buyers can now be written

$$
\begin{aligned}
& V^{b}(\hat{m}, \hat{a})=\eta\left[u\left(x^{N}\right)+W(0, \hat{a})\right] \\
& +(1-\eta)\left[u\left(x^{M}\right)+W(0, \hat{a}-e)\right] .
\end{aligned}
$$

Differentiating, we have

$$
\begin{aligned}
& \frac{\partial V^{b}}{\partial \hat{m}}=\eta u^{\prime}\left(x^{N}\right) \frac{\partial x^{N}}{\partial \hat{m}}+(1-\eta) u^{\prime}\left(x^{M}\right) \frac{\partial x^{M}}{\partial \hat{m}} \\
& -(1-\eta)(\psi+y) \frac{\partial e}{\partial \hat{m}} \\
& \frac{\partial V^{b}}{\partial \hat{a}}=\eta(\psi+y)+(1-\eta) u^{\prime}\left(x^{M}\right) \frac{\partial x^{M}}{\partial \hat{a}} \\
& +(1-\eta)(\psi+y)\left(1-\frac{\partial e}{\partial \hat{a}}\right),
\end{aligned}
$$

where from the bargaining solution we know the following ${ }^{31}$ :

$$
\begin{aligned}
& \hat{a}<a^{*} \Rightarrow \frac{\partial x^{N}}{\partial \hat{m}}=\phi ; \frac{\partial x^{M}}{\partial \hat{m}}=\phi ; \\
& \frac{\partial x^{M}}{\partial \hat{a}}=\psi+y ; \frac{\partial e}{\partial \hat{m}}=0 ; \frac{\partial e}{\partial \hat{a}}=1 \\
& \hat{a}>a^{*} \Rightarrow \frac{\partial x^{N}}{\partial \hat{m}}=\phi ; \frac{\partial x^{M}}{\partial \hat{m}}=0 ; \\
& \frac{\partial x^{M}}{\partial \hat{a}}=0 ; \frac{\partial e}{\partial \hat{m}}=\frac{-\phi}{\psi+y} ; \frac{\partial e}{\partial \hat{a}}=0
\end{aligned}
$$

In stationary equilibrium $\psi_{t+1}=\psi_{t}$ and $\phi_{t+1}=$ $\phi_{t} /(1+\mu)$, where again $\mu$ is both the rate of growth of $M_{t}$ and the inflation rate. Market clearing requires $\hat{a}=1$. There are then two possibilities for equilibrium: (i) liquidity is plentiful, $1>a^{*}$, which means that in monitored meetings agents have sufficient cash plus equity to buy $x^{*}$ while handing over only a fraction of their shares $e<1$; and (ii) liquidity is scarce, $1<a^{*}$, which means equity is in short enough supply that in monitored meetings buyers settle for $x^{M}<x^{*}$ while handing over all of their shares $e=1$. In case (i) we insert (19)-(20) into the FOC from the CM problem using (22) to get the relevant derivatives; and in case (ii) we do the same using (21). We now consider each case in turn. ${ }^{32}$

\subsection{Case (i)}

When $a^{*}<1$ and $x^{M}=x^{*}$, one could say liquidity is plentiful. Then the above procedure-inserting (19)-(20) into the FOC from equation (17) using equation (22)-yields

$$
\begin{aligned}
& \text { (23) } 1+\mu=\beta\left[\eta u^{\prime}\left(x^{N}\right)+1-\eta\right] \\
& \text { (24) } \psi=\beta(\psi+y) .
\end{aligned}
$$

Defining the interest rate on a nominal bond that is illiquid (cannot be traded in the DM) by $1+i=$ $(1+\mu) / \beta$, (23) can be written $i=\ell\left(x^{N}\right)$, where $\ell(x)=\eta\left[u^{\prime}(x)-1\right]$ is the formula for the liquidity premium when $\theta=1, c(x)=x$, and the relevant version of the single-coincidence probability is $\eta$. As in the model with money and no other assets, there is a unique $x^{N}>0$ solving this condition, and it would be correct to say that cash bears a liquidity premium.

By contrast, (24) tells us that equity is priced according to its fundamental value, the present value of its dividend stream, $\psi=\psi^{F} \equiv \beta y /(1-\beta)$. In this equilibrium, therefore, equity bears no liquidity premium, and its real return is invariant to inflation, as Irving Fisher would have it. To see when this equilibrium exists, the requirement $a^{*}<1$ is easily seen to hold iff $x^{*}<x^{N}+y /(1-\beta)$. Hence, if $y>(1-\beta) x^{*}$ this equilibrium always exists. And if $y<(1-\beta) x^{*}$ it exists iff $\mu<\bar{\mu}$, where

\footnotetext{
${ }^{31}$ Notice in particular that when $\hat{a}>a^{*}$, if we gave a buyer a little more $\hat{m}$ in a monitored meeting, he would not buy more $x^{M}$ but would reduce $e$ to $\operatorname{keep} x^{M}=x^{*}$.

${ }^{32}$ We ignore nongeneric cases throughout this section, where, say, buyers have just exactly enough liquidity to get $x^{M}=x^{*}$.
} 
(25) $1+\bar{\mu}=\beta\left[\eta u^{\prime}\left(x^{*}-\frac{y}{1-\beta}\right)+1-\eta\right]$,

since $x^{N} \rightarrow x^{*}$ as $\mu \rightarrow \beta-1$. An important conclusion is that even if equity is scarce, in the sense that $y<(1-\beta) x^{*}$, liquidity will not be scarce as long as inflation is low enough. Liquidity is always plentiful at the Friedman rule.

\subsection{Case (ii)}

When $1<a^{*}$ and $x^{M}<x^{*}$, one could say liquidity is scarce. Then the procedure described above yields

(26) $1+\mu=\beta\left[\eta u^{\prime}\left(x^{N}\right)+(1-\eta) u^{\prime}\left(x^{M}\right)\right]$

$$
\psi=\beta(\psi+y)\left[\eta+(1-\eta) u^{\prime}\left(x^{M}\right)\right]
$$

Immediately (26) tells us that equity trades in the $\mathrm{CM}$ for more than its fundamental price, $\psi>\psi^{F}$, as it now bears a liquidity premium. Using the bargaining solution $x^{M}=\phi m+\hat{a}(\psi+y)$ to eliminate $\psi$ from (27), we are left with two equations in $\left(x^{N}, x^{M}\right)$, which are easy to analyze. It is easy to check that in this equilibrium Fisher's theory does not apply to equity: An increase in inflation reduces the real rate of return of shares. The reason is that an increase in $\mu$ causes agents to, at the margin, shift their portfolio from cash into equity, driving up the share price $\psi$ and driving down the real return $y / \psi \cdot{ }^{33}$ This equilibrium exists iff $x^{M}<x^{*}$. This is the case if equity is scarce, $y<(1-\beta) x^{*}$, and additionally $\mu>\bar{\mu}$ where $\bar{\mu}$ is given in (25).

\subsection{Discussion}

To discuss optimality, for the sake of argument, let us add utilities across agents to construct a welfare measure

$$
\begin{aligned}
& \mathcal{W}=\eta\left[u\left(x^{N}\right)-x^{N}\right] \\
& +(1-\eta)\left[u\left(x^{M}\right)-x^{M}\right]-\omega x^{N}
\end{aligned}
$$

\footnotetext{
${ }^{33}$ For an illiquid bond, however, that cannot circulate in the DM, the Fisher equation still holds, of course.
}

where we take into account the cost of maintaining real money balances, $\omega \phi M=\omega x^{N}$. If $\omega=0$ then $\mathcal{W}$ is decreasing in $\mu$ and the optimal policy is the Friedman rule $\mu=\beta-1$. Given $\mu=\beta-1$, we achieve the first best $x^{M}=X^{N}=X^{*}$, shares trade at their fundamental price in the CM $\psi=\psi^{F}$, the real return on equity is $y / \psi=r$, and the nominal return is 0. Indeed, in a Friedman rule equilibrium, shares do not have to circulate in the DM, since outside money satiates agents in liquidity. We are not sure what to think of this result, however, since in practice private liquidity appears to be important for many transactions, and it is not clear that currency would replace it entirely even if monetary policy were optimal.

To get at this, we allow outside money to be costly by considering $\omega>0$, for reasons mentioned above concerning maintenance of the currency, protection against counterfeiting, and so on. Now at the Friedman rule $\mu=\beta-1$ we have $\partial \mathcal{W} / \partial \mu=$ $-\omega \partial x^{N} / \partial \mu>0$, so inflating above the Friedman rule is optimal. Suppose equity is plentiful at the optimum,

$$
\frac{\partial \mathcal{W}}{\partial \mu}=\left[\eta u^{\prime}\left(x^{N}\right)-\eta-\omega\right] \frac{\partial x^{N}}{\partial \mu}=0,
$$

and the optimal policy is

$$
\mu^{*}=\beta(1+\omega)-1
$$

This is the optimal policy, which means $y>$ $(1-\beta) x^{*}$, or $y<(1-\beta) x^{*}$ and $\mu^{*}>\bar{\mu}$. This will be the case iff $\omega<\bar{\omega}$ for some threshold $\bar{\omega}$. If, however, $y<(1-\beta) x^{*}$ and $\mu^{*}>\bar{\mu}$, which is the case iff $\omega>\bar{\omega}$, then equity is scarce at the optimum. In this case we cannot derive a closed-form solution for the optimal policy, but $\mu$ is still increasing in $\omega .^{34}$

For those who have not kept up with New Monetarist research, this example illustrates how it has moved beyond studying purely cash transactions. Related models, including Duffie Gârleanu, and Pederson (2005 and 2007); Vayanos and Weill (2008); Lagos (2008); Lagos and Rocheteau (2009); Lagos, Rocheteau, and Weill

\footnotetext{
${ }^{34}$ Effectively, the inflation tax falls on the users of currency, but at least for the case where shares are not scarce at the optimum, the inflation tax is not sufficient to finance currency maintenance.
} 
(2009); Rocheteau (2009), Ravikumar and Shao (2006), and Lester, Postlewaite, and Wright (2010), begin to address issues related to liquidity in asset markets, asset price volatility, the roles of public and private liquidity, and how informational frictions might matter. These models capture, in a simple way, optimal deviations from the Friedman rule. It is not common for monetary models, including reduced-form models, to produce an optimal deviation from the Friedman rule, yet central bankers typically target a short-term nominal interest rate of 0 only temporarily-if at all. At some level this is no different than policymakers using positive capital taxes or tariffs, binding minimum wage laws, rent control, agricultural price supports, and so on, which are all suboptimal according to textbook economics. Yet one might at least entertain the hypothesis that $i=0$ may be suboptimal.

New Keynesian sticky price models typically yield a deviation from the Friedman rule, with a zero inflation rate being the default option. We do not take those results very seriously, however, since those models leave out all the frictions that we think are relevant. For us, elements that are important in generating optimal departures from the Friedman rule might well include costs of operating currency systems, as captured in a simple way in the above example. He, Huang, and Wright (2008) and Sanches and Williamson (2010b) go into more detail analyzing explicit models of theft and show how this leads to the use of currency substitutes at the optimum. Similarly, Nosal and Wallace (2007) and Li and Rocheteau (2010) provide interesting analyses of counterfeiting. While currency maintenance, theft, counterfeiting, and so on are not usually considered first-order issues in mainstream monetary policy analysis, we think they are potentially important enough to take seriously. More work remains to be done on these issues.

\section{INTERMEDIATION}

While the model in Section 5 has some interesting features-for example, assets other than currency are used in transactions and can bear a liquidity premium -in practice, financial intermediation plays an important role in asset markets, and alternatives to currency in retail transactions are essentially always the liabilities of some private intermediary. Research from the 1980s on financial intermediation provides some alternative approaches to modeling intermediary structures in the class of models under consideration, including the framework of Diamond and Dybvig (1983), and costly-state-verification models like Diamond (1984) or Williamson (1986). Here we show how to integrate Diamond and Dybvig (1983) banking into our benchmark model, where banks provide insurance against the need for liquidity. Moreover, as in earlier attempts by Freeman (1988) or Champ, Smith, and Williamson (1996), in this model money and monetary policy play a role, while the original Diamond and Dybvig (1983) specification has neither currency nor anything that could be interpreted as the use of third-party liabilities facilitating transactions. ${ }^{35}$

The only alteration to the environment in Section 5 concerns the timing. Let's call buyers in a nonmonitored DM meeting type $N$ buyers and those in a monitored meeting type $M$ buyers. Then assume that buyers' types for the next DM are realized at the end of the current CM, after production and consumption decisions have been made but before they part company, and that this is publically observable. This allows buyers to enter into relationships that resemble banking. What is a bank? Any agent can offer the following deposit contract: "Make a deposit with me while the CM is still open, either in goods or money or other assets, it does not matter since I can adjust my portfolio frictionlessly in the CM; upon seeing your type, if it is $N$ you can withdraw $m^{N}$ dollars before going to the DM and retain claims to $a^{M}$ in the next CM; and if it is $M$ you withdraw nothing, but in the DM you can trade claims against your deposits backed by $m^{M}$ dollars and $a^{M}$ equity shares."

\footnotetext{
${ }^{35}$ The model in this section is related to the model of banking in Berentsen, Camera, and Waller (2007) and Chiu and Meh (2010), although it also goes beyond that work, in ways that we discuss below. A related analysis, using mechanism design, that also takes seriously the role of bank liabilities (deposits) in the exchange process is developed in Mattesini, Monnet, and Wright (2010).
} 
The fact that deposit claims are transferable, allows them to potentially be traded in the DM, but to make things interesting here we treat them symmetrically with actual shares as in Section 5they can be phony, and only sellers in monitored meetings can verify this, and therefore only sellers in monitored meetings accept these claims.

Banks are competitive, so the equilibrium contract maximizes the welfare of a representative depositor, subject to non-negative profit, and a bank can diversify perfectly against its customers ending up type $N$ or $M$ as long as it attracts a strictly positive mass (although it would also be interesting to add aggregate uncertainty). Suppose the representative buyer acquires and then deposits $\hat{m}$ and $\hat{a}$, where we can restrict attention to the case where buyers bank all their assets. Also, without loss of generality, we can restrict attention to contracts with $m^{N}>0$ and $a^{N}=0$, since buyers have no use for equity in nonmonitored meetings, and therefore to contracts where $a^{M}=\hat{a} /(1-\eta)$, but we have to sort out below whether $m^{M}>0$ or $m^{M}=0$; all we know so far is that $\eta m^{N}+$ $(1-\eta) m^{M}=\hat{m}$. We maintain the assumptions that buyers make take-it-or-leave-it offers in the DM and $c(x)=x$, so that $x^{N}=\phi m^{N}$ and $x^{M}=\phi m^{M}+$ $e(\psi+y)$, as before, except now type $N$ buyers go to the DM with $m^{N}$ dollars while type $M$ go with transferable deposits of $m^{N}$ dollars plus $\hat{a} /(1-\eta)$ shares. Still it should be clear that we can again take the following for granted: $d^{N}=m^{N} ; d^{M}=m^{M}$; $e=\hat{a} /(1-\eta)$ if $\hat{a} /(1-\eta)<a^{*}$ and $e=a^{*}$ otherwise; $x^{N}<x^{*}$; and, finally, $x^{M}=\phi m^{M}+(\psi+y) \hat{a} /(1-\eta)$ if $\hat{a}<a^{*}$ and $x^{M}=x^{*}$.

The objective function for a buyer, and hence for a competitive banker, is exactly $W^{b}(\cdot)$ as written in (17), except now

$$
\begin{aligned}
& V^{b}(\hat{m}, \hat{a})=\eta\left[u\left(x^{N}\right)+W^{b}(0,0)\right] \\
& +(1-\eta)\left[u\left(x^{M}\right)+W^{b}\left(0, \frac{\hat{a}}{1-\eta}-e\right)\right]
\end{aligned}
$$

where $x^{N}=\phi m^{N}$ and $x^{M}=\phi m^{M}+e(\psi+y)$. The same procedure used in Section 5 applies: Insert into the FOC the derivatives of $V^{b}(\cdot)$ from (30) taking care of whether $\hat{a} /(1-\eta)>a^{*}$ or vice versa, and also whether $m^{M}=0$ or $m^{M}>0$. When $\hat{a} /(1-\eta)>a^{*}$ it should be clear that $m^{M}=0$, since type $M$ buyers are already satiated in liquidity without cash. Also, market clearing implies $\hat{a}=1$ and $\hat{m}=M(1+\mu)$. Hence, in this model, there are three possibilities for equilibrium: (i) $1>a^{*}(1-\eta)$ which implies $m^{M}=0$ and $x^{M}=x^{*}$; (ii) $1<a^{*}(1-\eta)$ and $m^{M}=0$, which implies $x^{M}<x^{*}$; and (iii) $1<$ $a^{*}(1-\eta)$ and $m^{M}>0$, which also implies $x^{M}<x^{*}$. Again, we study each case in turn.

\subsection{Case (i)}

In this case the supply of equity is plentiful enough that type $M$ buyers are satiated in liquidity, $1>a^{*}(1-\eta)$ which implies $x^{M}=x^{*}$ and $m^{M}=0$, and therefore $m^{N}=M / \eta$. The procedure described above immediately yields

(31) $1+\mu=\beta u^{\prime}\left(x^{N}\right)$

$$
\psi=\beta(\psi+y)
$$

Thus, equity trades at its fundamental value in the CM, $\psi=\psi^{F}$, and $x^{N}$ satisfies the usual condition, which as above could also be written $i=\ell\left(x^{N}\right)$. For this equilibrium to exist, we require $1>$ $a^{*}(1-\eta)$, which holds in this case iff

(33) $y>(1-\eta)(1-\beta) x^{*}$.

Also, in this case, the real rate of return on shares is $1 / \beta-1$ independent of $\mu$, and there is a standard Fisher effect.

\subsection{Case (ii)}

The by now standard procedure tells us that $X^{N}$ solves (31), the same as in the previous case. However, (32) becomes

$$
\psi=\beta(\psi+y) u^{\prime}\left(x^{M}\right)
$$

where $x^{M}<x^{*}$ implies $\psi>\psi^{F}$. Equity now bears a liquidity premium because it is scarce-even though type $M$ buyers are able to offer $1 /(1-\eta)$ shares, it is not enough to get $x^{*}$. Using the bargaining solution, which in this case entails $x^{M}=(\psi+y) /(1-\eta)$, to eliminate $\psi$ in (34) yields a simple equation in $x^{M}$. Notice, interestingly enough, that $x^{M}$ and hence $\psi$ are independent of $\mu$ in this case. One can show that for this equilibrium to exist we require that the inequality in (34) 
goes the other way, and in addition, we must verify that $m^{M}=0$ is part of the equilibrium deposit contract. It is straightforward to show this is the case iff $\mu \geq \tilde{\mu}$, where $\tilde{\mu} \in(\beta-1,0)$ solves

$$
u^{\prime}\left[\frac{y}{(1-\eta) \tilde{\mu}}\right]=\frac{1+\tilde{\mu}}{\beta} \text {. }
$$

Notice the real return on shares is below 1 / $\beta$ but above the real return on money in this equilibrium. The gross nominal interest rate on shares is

$$
(1+\mu)\left(\frac{\psi+y}{\psi}\right)
$$

where $\mu>\tilde{\mu}$, and

$$
\frac{1+\mu}{\beta}>(1+\mu)\left(\frac{\psi+y}{\psi}\right)>1 .
$$

Hence, the nominal interest rate on shares is positive when $\mu>\tilde{\mu}$, although when $\mu=\tilde{\mu}$ it goes to zero. Letting $r^{j}$ denote the real rate of return faced by a type $j$ buyer, from (31) and (32) we have

$$
r^{j}=\frac{x^{j}}{\eta(1+\mu) x^{N}+(1-\eta) \frac{\psi}{\psi+y} x^{M}} .
$$

As well the gross nominal interest rate on deposits is

$$
(1+\mu) r^{M}=\frac{x^{M}}{\eta X^{N}+(1-\eta) \frac{\psi}{(1+\mu)(\psi+y)} x^{M}} .
$$

Thus, the nominal interest rate on deposits is positive when $x^{N}<X^{M}$ and

$$
\frac{\psi+y}{\psi}>\frac{1}{1+\mu}
$$

and zero when $x^{N}=x^{M}$ and

$$
\frac{\psi+y}{\psi}=\frac{1}{1+\mu} .
$$

\subsection{Case (iii)}

In this case the deposit contract sets $m^{M}>0$ as well as $m^{N}>0$ and $\hat{a}>0$. It is easily shown that the equilibrium contract equates DM consumption for type $M$ and type $N$ buyers, $X^{M}=X^{N}$, and we call the common value $x<x^{*}$. Also, we have
(35) $1+\mu=\beta u^{\prime}(x)$

(36) $\psi=\beta(\psi+y) u^{\prime}(x)$.

By (35), $x$ is given by the usual condition in monetary trades, and (36) determines $\psi>\psi^{F}$. One can show this equilibrium exists iff the inequality in (33) again goes the other way and $\mu \in[\beta-1, \tilde{\mu}]$.

Note that in this equilibrium the gross return on shares is below $1 / \beta$, but since the real returns on shares and money are identical, the nominal interest rate on shares is 0 , as is the nominal interest rate on deposits. Another interesting feature of this case is that an increase in the money growth rate increases the price of shares, has no effect on the nominal interest rate, and reduces the real interest rate. Further, banks hold reserves in equilibrium. Simplistic intuition might tell us that, given the zero nominal rate, monetary policy would encounter some kind of liquidity trap. But changes in the money growth rate $\mu$ will change the real allocation, despite the fact that it brings about a change in the quantity of reserves and no change in the nominal rate. So much for simplistic intuition.

\subsection{Discussion}

The principal role of a bank here is to allocate public and private liquidity to its most efficient uses in transactions. Without banking, some buyers show up in non-monitored DM meetings with shares that are not accepted, while others show up in monitored DM meetings with money that is dominated in rate of return by shares that are equally acceptable. Buyers would be better off if they knew in advance their type (monitored or nonmonitored) in the next DM. If they knew this, they would typically take only cash to nonmonitored meetings and only equity to monitored meetings. Essentially, with banking it is as if buyers knew in advance their type, which in this case corresponds to their need for currency. Banking allows shares to be concentrated in monitored meetings, so more private liquidity can be allocated to where it is useful, and currency to be allocated to nonmonitored meetings where it has 
an advantage in terms of acceptability, except in the case where public liquidity is useful at the margin for sharing risk between type 1 and type 2 buyers (the case where the bank holds reserves). This is related to, but also goes beyond, the New Monetarist banking model of Berentsen, Camera, and Waller (2007), where the only role of banks is to allocate currency between buyers and sellers. One advantage of including alternative assets is that we can provide a link between liquidity provision and media of exchange, on the one hand, and investment, on the other; see Williamson (2009) for more on this topic.

One can use this simple banking model to shed new light on several issues. In terms of optimal policy, since the cost of maintaining the currency is now $\eta \omega x^{N}$, our welfare measure becomes

$$
\begin{aligned}
& W=\eta\left[u\left(x^{N}\right)-x^{N}\right] \\
& +(1-\eta)\left[u\left(x^{M}\right)-x^{M}\right]-\eta \omega x^{N} .
\end{aligned}
$$

Notice that outside money held as reserves costs nothing to maintain, as this can be interpreted as electronic account balances with the central bank. If $\omega=0$, then the Friedman rule $\mu=\beta-1$ is optimal, we get the first best using currency, and banks become irrelevant (buyers can do just as well trading on their own). However, if $\omega>0$, then $\mu>\beta-1$ is optimal. There are three cases to consider.

If (33) holds, so deposits are not scarce for any $\mu$, the optimal policy entails $\mu=\beta(1+\omega)-1$ and the nominal interest rates on shares and deposits are strictly positive. If inequality (33) goes the other way, $\beta(1+\eta \omega)<1$ and

$$
u^{\prime}\left[\frac{y}{(1-\eta)[1-\beta(1+\eta \omega)]}\right] \geq 1+\eta \omega,
$$

then the optimal policy is $\mu=\beta(1+\eta \omega)-1$. In this case, at the optimum, $\mu \geq \tilde{\mu}$, shares are scarce, the nominal interest rate is zero, and the real interest rate is below the rate of time preference. This is novel, in that the usual Friedman rule prescription is to equate real rates of return on all assets, so that the nominal interest rate should be 0 . But if $\omega=0$, we would reduce the money growth rate to $\mu=\beta-1$, which would increase the real rate of interest to the rate of time preference. Finally, if (33) goes the other way and either $\beta(1+\eta \omega) \geq 1$ or

$$
u^{\prime}\left[\frac{y}{(1-\eta)[1-\beta(1+\eta \omega)]}\right]<1+\eta \omega,
$$

then $\mu=\beta(1+\omega)-1$ at the optimum.

In summary, in this model, as long as $\omega>0$ banks perform a socially useful function. ${ }^{36} \mathrm{We}$ now use the model to discuss Friedman's (1960) proposal for 100 percent reserve requirements on all transactions deposits, a scheme sometimes referred to as narrow banking. His reasoning was that variability in real economic activity and in the price level arises, perhaps primarily, from variability in the money stock measured by currency in circulation plus transactions deposits. The central bank cannot control inside money, the quantity of transactions deposits, directly, but only the quantity of outside money. However, if all transactions deposits are backed 100 percent by outside money, then the central bank can control the total stock of money perfectly, and can thus cure monetary instability. According to the model presented above, however, this is wrong.

We start with Friedman's premise, which is informed by the quantity theory, that the behavior of some monetary aggregate like M1 is important. In the model, M1 in the DM of period $t+1$ is

$$
M 1_{t+1}=M_{t}+\frac{(\psi+y)}{\phi_{t+1}}=M_{t}\left(\frac{\eta x_{t+1}^{N}+\psi+y}{\eta x_{t+1}^{N}}\right)
$$

in equilibria where no bank reserves are held and

$$
M 1_{t+1}=M_{t}\left(\frac{x_{t+1}-\psi-y}{x_{t+1}}\right)
$$

in equilibria where bank reserves are positive. Here, $x_{t+1}^{N}$ denotes the consumption of type $N$ buyers in the DM when no bank reserves are held, and $x_{t+1}$ is the consumption of each buyer in the DM when bank reserves are positive. In (37) and (38), the expression in parentheses in each equa-

\footnotetext{
${ }^{36}$ Adding theft or counterfeiting to the model makes banks even more useful. Indeed, stories about the need for the safekeeping of liquid assets are often used to help students understand how banks developed as institutions that link the provision of transactions services with portfolio management. See He, Huang, and Wright (2008) for an explicit New Monetarist model of theft and the safekeeping role of banks.
} 
tion is the money multiplier, which plays an important role, for example, in the interpretation of historical data by Friedman and Schwartz (1963).

It is hard to think of an interesting question to which the money multiplier would help us with the answer. The reason is that the money multiplier is not invariant to most policy experiments, except for simple one-time increases in the stock of outside money. Since money is neutral, the multiplier does not depend on the level of the money supply, so the multiplier tells us how much M1 increases per unit increase in the stock of base money. Beyond that, we know that $x_{t+1}^{N}$ depends on $\mu$ in (37) and $\psi$ and $x_{t+1}$ depend on $\mu$ in (38). The model tells us the details of how a change in $\mu$ affects prices and quantities. However, the quantity theory of money does not help us organize our thinking about banks, liquidity, or exchange in this context. Similar ideas apply for other types of monetary policy experiments. If we want to understand the effects of central bank lending and open market operations, as in Williamson (2009), for example, money multiplier analysis does not seem to help.

Note as well that theory provides no particular rationale for adding up certain public and private liabilities (in this case currency and bank deposits), calling the sum money, and attaching some special significance to it. Indeed, there are equilibria in the model where currency and bank deposits are both used in some of the same transactions, both bear the same rate of return, and the stocks of both turn over once each period. Thus, Friedman, if he were alive, might think he had good reason to call the sum of currency and bank deposits money and proceed from there. But what the model tells us is that public and private liquidity play quite different roles. In reality, many assets are used in transactions, broadly defined, including Treasury bills, mortgage-backed securities, and mutual fund shares. We see no real purpose in drawing some boundary between one set of assets and another, and calling members of one set money. ${ }^{37}$

\footnotetext{
${ }^{37}$ Related discussions can be found in Wallace (1980) and Sargent and Wallace (1982); in a sense we are just restating their ideas in the context of our New Monetarist model.
}

Suppose the government were to, misguidedly as it turns out, impose 100 percent reserve requirements. At best, this would be a requirement that outside money be held one-for-one against bank deposits. We are now effectively back to the world of the model without banks in the previous section, as holding bank deposits becomes equivalent to holding currency. Agents receive no liquidity insurance, and are worse off than with unfettered banking, since the efficiency gains from the reallocation of liquidity are lost. At worst, suppose the 100 percent reserve requirement is imposed by constraining every transaction to be a trade of outside money for something else, so that shares cannot be used at all in transactions. Then shares will be held from one CM until the next, never trading in the DM, and any benefits from private liquidity are forgone. This obviously reduces welfare. A flaw in Old Monetarism was that it neglected the role of intermediation in allocating resources efficiently. In other related environments (e.g., Williamson, 1999 and 2009, and some examples presented in Williamson and Wright, forthcoming), banks can also be important in reallocating investment and capital efficiently, with the transactions role of bank liabilities being critical in attracting savings to financial intermediaries that can be channeled into investment. In spite of the weaknesses in the quantity theory of money, the reasoning behind the Friedman rule is impeccable, and we take that to be the important legacy of Old Monetarism.

\section{CONCLUSION}

New Monetarist economists are committed to modeling approaches that are explicit about the frictions that make monetary exchange and related arrangements socially useful and that capture the relationships among credit, banking, and currency transactions. Ideally, economic theories designed for analyzing and evaluating monetary policy should be able to answer basic questions concerning the necessity and role of central banking, the superiority of one type of central bank operating procedure over another, and the differences in the effects of central bank 
lending and open market operations. New Monetarist economists have made progress in understanding the basic frictions that make monetary exchange an equilibrium or an efficient arrangement, and in understanding the mechanisms by which policy can affect allocations and welfare. However, much remains to be learned about many issues, including the sources of shortrun nonneutralities and their quantitative significance, as well as the role of central banking.

With the examples in this paper, and some other examples in our companion paper (Williamson and Wright, forthcoming) concerning payments systems, labor markets, investment, and several other substantive applications, we hope to give some of the flavor of frontier work in the New Monetarist research program. Our principles and our modeling approaches developed thus far have great potential in explaining asset pricing anomalies; the role of public and private liquidity in transactions, both at the retail level and among financial institutions; the functions of collateral; and the relationship between money and credit. Recent events in financial markets and in the broader economy make it clear how important it is to model basic frictions in the financial system. We look forward to developments in this research and are excited about the future prospects for New Monetarism.

\section{REFERENCES}

Aliprantis, Charalambos D.; Camera, Gabrielle and Puzzello, Daniela. "Matching and Anonymity." Economic Theory, October 2006, 29(2), pp. 415-32.

Aliprantis, Charalambos D.; Camera, Gabrielle and Puzzello, Daniela. "Anonymous Markets and Monetary Trading.” Journal of Monetary Economics, October 2007, 54(7), pp. 1905-28.

Araujo, Luis; Camargo, Braz; Minetti, Raoul and Puzzello, Daniela. "The Informational Role of Prices and the Essentiality of Money in the Lagos-Wright Model.” Unpublished manuscript, Michigan State University, 2010.

Aruoba, S. Borağan; Rocheteau, Guillaume and Waller, Christopher. "Bargaining and the Value of Money." Journal of Monetary Economics, November 2007, 54(8), pp. 2636-55.

Aruoba, S. Borağan and Schorfheide, Frank. "Sticky Prices versus Monetary Frictions: An Estimation of Policy Tradeoffs.” American Economic Journal: Macroeconomics, 2010 (forthcoming).

Aruoba, S. Borağan; Waller, Christopher and Wright, Randall. "Money and Capital: A Quantitative Analysis." Working paper, University of Maryland, 2009.

Ball, Laurence and Mankiw, N. Gregory. “A Sticky Price Manifesto.” Unpublished manuscript, 1994.

Barro, Robert. "Long-Term Contracting, Sticky Prices, and Monetary Policy.” Journal of Monetary Economics, July 1977, 3(3), pp. 305-16.

Bassetto, Marco. “A Game-Theoretic View of the Fiscal Theory of the Price Level.” Econometrica, November 2002, 70(6), pp. 2167-95.

Basu, Susanto and Fernald, John G. "Returns to Scale in U.S. Production: Estimates and Implications." Journal of Political Economy, April 1997, 105(2), pp. 249-83.

Baumol, William. “The Transactions Demand for Cash: An Inventory Theoretic Approach.” Quarterly Journal of Economics, November 1952, 66(4), pp. 545-56.

Berentsen, Aleksander; Camera, Gabriele and Waller, Christopher. "The Distribution of Money Balances and the Nonneutrality of Money." International Economic Review, May 2005, 46(2), pp. 465-87.

Berentsen, Aleksander; Camera, Gabriele and Waller, Christopher. "Money, Credit, and Banking.” Journal of Economic Theory, July 2007, 135(1), pp. 171-95. 


\section{Williamson and Wright}

Berentsen, Aleksander; Menzio, Guido and Wright, Randall. "Inflation and Unemployment in the Long Run." American Economic Review, 2010 (forthcoming).

Berentsen, Aleksander and Waller, Christopher. "Optimal Stabilization Policy with Endogenous Firm Entry." Working Paper 2009-032, Federal Reserve Bank of St. Louis, August 2009;

http://research.stlouisfed.org/wp/2009/2009-032.pdf.

Bernanke, Ben S. and Gertler, Mark. “Agency Costs, Net Worth, and Business Fluctuations.” American Economic Review, March 1989, 79(1), pp. 14-31.

Brock, William A. "Overlapping Generations Models with Money and Transactions Costs,” in Benjamin M. Friedman and Frank H. Hahn, eds., Handbook of Monetary Economics. Chap. 7. Amsterdam: North-Holland, 1990.

Buiter, Willem H. "The Macroeconomics of Dr. Pangloss: A Critical Survey of the New Classical Macroeconomics." Economic Journal, March 1980, 90(357), pp. 34-50.

Burdett, Kenneth; Trejos, Alberto and Wright, Randall. "Cigarette Money.” Journal of Economic Theory, July 2001, 99(1-2), pp. 117-42.

Bryant, John and Wallace, Neil. “The Inefficiency of Interest-Bearing Government Debt.” Journal of Political Economy, April 1979, 87(2), pp. 365-81.

Bryant, John and Wallace, Neil. “A Price Discrimination Analysis of Monetary Policy.” Review of Economic Studies, April 1984, 51(165), pp. 279-88.

Calvo, Guillermo. "Staggered Prices in a Utility-Maximizing Framework.” Journal of Monetary Economics, September 1983, 12(3), pp. 383-98.

Camera, Gabriele and Corbae, P. Dean. "Money and Price Dispersion." International Economic Review, November 1999, 40(4), pp. 985-1008.

Caplin, Andrew and Spulber, Daniel. "Menu Costs and the Neutrality of Money." Quarterly Journal of Economics, November 1987, 102(4), pp. 703-25.

Champ, Bruce; Smith, Bruce D. and Williamson, Stephen. "Currency Elasticity and Banking Panics: Theory and Evidence." Canadian Journal of Economics, November 1996, 29(4), pp. 828-64.

Chiu, Jonathan and Meh, Césaire. "Banking, Liquidity, and Inflation.” Macroeconomic Dynamics, 2010 (forthcoming).

Chiu, Jonathan and Molico, Miguel. "Liquidity, Redistribution, and the Welfare Cost of Inflation." Journal of Monetary Economics, May 2010, 57(4), pp. 428-38.

Chiu, Jonathan and Molico, Miguel. “Uncertainty, Inflation, and Welfare.” Working paper, Bank of Canada, 2008.

Clarida, Richard; Gali, Jordi and Gertler, Mark. "The Science of Monetary Policy: A New Keynesian Perspective." Journal of Economic Literature, December 1999, 37(4), pp. 1661-707.

Coase, Ronald. “The Nature of the Firm.” Economica, November 1937, 4(16), pp. 386-405.

Cooley, Thomas and Hansen, Gary. "The Inflation Tax in a Real Business Cycle Model.” American Economic Review, September 1989, 79(4), pp. 733-48.

Corbae, P. Dean; Temzelides, Ted and Wright, Randall. "Directed Matching and Monetary Exchange.” Econometrica, May 2003, 71(3), pp. 731-56.

Craig, Ben and Rocheteau, Guillaume. "State-Dependent Pricing, Inflation, and Welfare in Search Economies." European Economic Review, April 2008, 52(3), pp. 441-68. 
Curdia, Vasco and Woodford, Michael. "Conventional and Unconventional Monetary Policy." CEPR Discussion Paper 7514, Centre for Economic Policy Research, October 2009.

Diamond, Douglas. "Financial Intermediation and Delegated Monitoring." Review of Economic Studies, July 1984, 51(166), pp. 393-414.

Diamond, Douglas and Dybvig, Philip. "Bank Runs, Deposit Insurance, and Liquidity.” Journal of Political Economy, June 1983, 91(3), pp. 401-19.

Diamond, Peter. “Money in Search Equilibrium.” Econometrica, January 1984, 52(1), pp. 1-20.

Dong, Mei and Jiang, Jing. "Money and Price Posting under Private Information.” Unpublished manuscript, Bank of Canada, 2009.

Dressler, Scott J. "Money Holdings, Inflation, and Welfare in a Competitive Market.” International Economic Review, 2010 (forthcoming).

Dressler, Scott J. "Inflation and Welfare Dynamics in a Competitive Market.” Unpublished manuscript, Villanova University, 2010.

Duffie, Darrell; Gârleanu, Nicolae and Pederson, Lasse H. “Over-the-Counter Markets.” Econometrica, November 2005, 73(6), pp. 1815-47.

Duffie, Darrell; Gârleanu, Nicolae and Pederson, Lasse H. "Valuation in Over-the-Counter Markets." Review of Financial Studies, November 2007, 20(6), pp. 1865-900.

Dutu, Richard; Julien, Benoit and King, Ian. "Liquidity Constrained Competing Auctions.” Working Papers 1068, University of Melbourne Department of Economics, April 2009.

Ennis, Huberto. "Search, Money, and Inflation under Private Information." Journal of Economic Theory, January 2008, 138(1), pp. 101-31.

Ennis, Huberto. “Avoiding the Inflation Tax.” International Economic Review, May 2009, 50(2), pp. 607-25.

Ennis, Huberto and Keister, Todd. "Bank Runs and Institutions: The Perils of Intervention." American Economic Review, September 2009a, 99(4), pp. 1588-607.

Ennis, Huberto and Keister, Todd. "Run Equilibria in the Green-Lin Model of Financial Intermediation." Journal of Economic Theory, September 2009b, 144(5), pp. 1996-2020.

Faig, Miguel and Jerez, Belén. “A Theory of Commerce.” Journal of Economic Theory, May 2005, 122(1), pp. 60-99.

Freeman, Scott J. “Banking as the Provision of Liquidity.” Journal of Business, January 1988, 61(1), pp. 45-64.

Freeman, Scott J. “The Payments System, Liquidity, and Rediscounting.” American Economic Review, December 1996, 86(5), pp. 1126-38.

Friedman, Milton. A Theory of the Consumption Function. Princeton: Princeton University Press, 1957.

Friedman, Milton. A Program for Monetary Stability. New York: Fordham University Press, 1960.

Friedman, Milton. “The Role of Monetary Policy.” American Economic Review, March 1968, 58(1), pp. 1-17.

Friedman, Milton. The Optimum Quantity of Money and Other Essays. New York: Aldine Publishing Company, 1969.

Friedman, Milton and Schwartz, Anna J. A Monetary History of the United States, 1867-1960. Cambridge, MA: National Bureau of Economic Research, 1963.

Galenianos, Manolis and Kircher, Philipp. "A Model of Money with Multilateral Matching.” Journal of Monetary Economics, September 2008, 55(6), pp. 1054-66. 


\section{Williamson and Wright}

Geromichalos, Athanasios; Licari, Juan M. and Suarez-Lledo, José. "Monetary Policy and Asset Prices.” Review of Economic Dynamics, October 2007, 10(4), pp. 761-79.

Gertler, Mark and Trigari, Antonella. "Unemployment Fluctuations with Staggered Nash Wage Bargaining." Journal of Political Economy, February 2009, 117(1), pp. 38-86.

Goodfriend, Marvin. "How the World Achieved Consensus on Monetary Policy.” Journal of Economic Perspectives, Fall 2007, 21(4), pp. 47-68.

Green, Edward and Zhou, Ruilin. "A Rudimentary Random-Matching Model with Divisible Money and Prices." Journal of Economic Theory, August 1998, 81(2), pp. 252-71.

Hahn, Frank H. "On the Foundations of Monetary Theory,” in Michael Parkin and A. Robert Nobay, eds., Essays in Modern Economics. New York: Barnes \& Noble, 1973.

He, Ping; Huang, Lixin and Wright, Randall. “Money, Banking, and Monetary Policy.” Journal of Monetary Economics, September 2008, 55(6), pp. 1013-24.

Head, Allen; Liu, Lucy Q.; Menzio, Guido and Wright, Randall. “Sticky Prices?” Unpublished manuscript, Queen's University, 2010.

Hicks, John R. “A Suggestion for Simplifying the Theory of Money.” Economica, February 1935, 2(5), pp. 1-19.

Hicks, John R. “Mr. Keynes and the 'Classics': A Suggested Interpretation.” Econometrica, April 1937, 5(2), pp. 147-59.

Hosios, Arthur J. "On the Efficiency of Matching and Related Models of Search and Unemployment." Review of Economic Studies, April 1990, 57(2), pp. 279-98.

Howitt, Peter. "Beyond Search: Fiat Money in Organized Exchange.” International Economic Review, May 2005, 46(2), pp. 405-29.

Hu, Tai-wei; Kennan, John and Wallace, Neil. "Coalition-Proof Trade and the Friedman Rule in the Lagos-Wright Model.” Journal of Political Economy, February 2009, 117(1), pp. 116-37.

Huggett, Mark. “The Risk-Free Rate in Heterogeneous-Agent Incomplete-Insurance Economies.” Journal of Economic Dynamics and Control, September/November 1993, 17(5/6), pp. 953-69.

Jean, Kasie; Stanislav, Rabinovich and Wright, Randall. "On the Multiplicity of Monetary Equilibria Green-Zhou Meets Lagos-Wright.” Journal of Economic Theory, January 2010, 145(1), pp. 392-401.

Jevons, William S. Money and the Mechanism of Exchange. London: Appleton, 1875.

Jones, Robert A. “The Origin and Development of Media of Exchange.” Journal of Political Economy, August 1976, 84(4), pp. 757-75.

Julien, Benoit; Kennes, John and King, Ian. "Bidding For Money.” Journal of Economic Theory, September 2008, 142(1), pp. 196-217.

Kareken, John H. and Wallace, Neil. Models of Monetary Economies. Minneapolis: Federal Reserve Bank of Minneapolis, 1980.

Kiyotaki, Nobuhiro and Wright, Randall. “On Money as a Medium of Exchange.” Journal of Political Economy, August 1989, 97(4), pp. 927-54.

Kiyotaki, Nobuhiro and Wright, Randall. "A Contribution to the Pure Theory of Money." Journal of Economic Theory, April 1991, 53(2), pp. 215-35.

Kiyotaki, Nobuhiro and Wright, Randall. "A Search-Theoretic Approach to Monetary Economics.” American Economic Review, March 1993, 83(1), pp. 63-77. 
Keynes, John M. A Tract on Monetary Reform. Amherst, NY: Prometheus Books, 1924.

Keynes, John M. The General Theory of Employment, Interest and Money. Cambridge, MA: Macmillan Cambridge University Press, 1936.

Klenow, Peter and Malin, Benjamin A. "Microeconomic Evidence on Price-Setting," in Handbook of Monetary Economics. Volume 3A. (forthcoming).

Kocherlakota, Narayana R. "Money is Memory.” Journal of Economic Theory, August 1998, 81(2), pp. 232-51.

Krugman, Paul. “How Did Economists Get It So Wrong?” New York Times Magazine, September 2, 2009.

Krusell, Per and Smith, Anthony A. "Income and Wealth Heterogeneity in the Macroeconomy." Journal of Political Economy, October 1998, 106(5), pp. 867-96.

Krishnamurthy, Arvind and Vissing-Jorgensen, Annette. "The Aggregate Demand for Treasury Debt.” Unpublished manuscript, Northwestern University, 2009.

Lagos, Ricardo. "Asset Prices and Liquidity in an Exchange Economy.” Working paper, New York University, May 2008.

Lagos, Ricardo and Rocheteau, Guillaume. "Inflation, Output, and Welfare.” International Economic Review, May 2005, 46(2), pp. 495-522.

Lagos, Ricardo and Rocheteau, Guillaume. "Money and Capital as Competing Media of Exchange." Journal of Economic Theory, September 2008, 142(1), pp. 247-58.

Lagos, Ricardo and Rocheteau, Guillaume. "Liquidity in Asset Markets with Search Frictions." Econometrica, March 2009, 77(2), pp. 403-26.

Lagos, Ricardo; Rocheteau, Guillaume and Weill, Pierre-Olivier. "Crises and Liquidity in Over-the-Counter Markets.” Unpublished manuscript, New York University, 2009.

Lagos, Ricardo and Wright, Randall. "Dynamics, Cycles and Sunspot Equilibria in 'Genuinely Dynamic, Fundamentally Disaggregative’ Models of Money.” Journal of Economic Theory, April 2003, 109(2), pp. 156-71.

Lagos, Ricardo and Wright, Randall. “A Unified Framework for Monetary Theory and Policy Analysis.” Journal of Political Economy, June 2005, 113(3), pp. 463-84.

Leijonhufvud, Axel. On Keynesian Economics and the Economics of Keynes: A Study in Monetary Theory. London: Oxford University Press, 1968.

Lester, Benjamin; Postlewaite, Andrew and Wright, Randall. "Information and Liquidity.” Unpublished manuscript, 2009 (forthcoming in Journal of Money, Credit, and Banking).

Lester, Benjamin; Postlewaite, Andrew and Wright, Randall. "Liquidity, Information, Asset Prices and Monetary Policy.” Working paper, University of Pennsylvania, 2010.

Li, Victor E. "Inventory Accumulation in a Search-Based Monetary Economy." Journal of Monetary Economics, December 1994, 34(3), pp. 511-36.

Li, Victor E. “The Optimal Taxation of Fiat Money in Search Equilibrium.” International Economic Review, November 1995, 36(4), pp. 927-42.

Li, Yiting and Rocheteau, Guillaume. "The Threat of Counterfeiting.” Macroeconomic Dynamics, 2010 (forthcoming).

Liu, Lucy; Wang, Liang and Wright, Randall. “On the 'Hot Potato' Effect of Inflation: Intensive versus Extensive Margins.” Macroeconomic Dynamics, 2010 (forthcoming).

Lucas, Robert E. "Expectations and the Neutrality of Money." Journal of Economic Theory, April 1972, 4(2), pp. 103-24. 


\section{Williamson and Wright}

Lucas, Robert E. "Econometric Policy Evaluation: A Critique.” Carnegie-Rochester Conference Series on Public Policy, January 1976, 1(1), pp. 19-46.

Lucas, Robert E. “Asset Prices in an Exchange Economy.” Econometrica, November 1978, 46(6), pp. 1429-45.

Lucas, Robert E. "Methods and Problems in Business Cycle Theory." Journal of Money, Credit, and Banking, November 1980a, 12(4), pp. 696-715.

Lucas, Robert E. "Equilibrium in a Pure Currency Economy,” in John Kareken and Neil Wallace, eds., Models of Monetary Economies. Minneapolis: Federal Reserve Bank of Minneapolis, 1980b, pp. 131-45.

Lucas, Robert E. “Inflation and Welfare.” Econometrica, March 2000, 68(2), pp. 247-74.

Lucas, Robert E. and Prescott, Edward C. "Equilibrium Search and Unemployment.” Journal of Economic Theory, February 1974, 7(2), pp. 188-209.

Mayer, Thomas; Duesenberry, James S. and Aliber, Robert Z. Money, Banking, and the Economy. New York: Norton, 1981.

Mankiw, N. Gregory. "Small Menu Costs and Large Business Cycles: A Macroeconomic Model." Quarterly Journal of Economics, May 1985, 100(2), pp. 529-38.

Mankiw, N. Gregory and Reis, Ricardo. "Sticky Information Versus Sticky Prices: A Proposal to Replace the New Keynesian Phillips Curve.” Quarterly Journal of Economics, November 2002 , 117(4), pp. 1295-328.

Mattesini, Fabrizio; Monnet, Cyril and Wright, Randall. "Banking: A Mechanism Design Approach.” Unpublished manuscript, Federal Reserve Bank of Philadelphia, 2010.

Menger, Carl. “On the Origin of Money.” Economic Journal, 1892, 2(6), pp. 239-55.

Molico, Miguel. "The Distribution of Money and Prices in Search Equilibrium." International Economic Review, August 2006, 47(3), pp. 701-22.

Mortensen, Dale T. and Pissarides, Christopher A. "Job Creation and Job Destruction in the Theory of Unemployment.” Review of Economic Studies, July 1994, 61(3), pp. 397-416.

Nosal, Ed. “Search, Welfare and the 'Hot Potato’ Effect of Inflation.” Macroeconomic Dynamics, 2010 (forthcoming).

Nosal, Ed and Rocheteau, Guillaume. "Money, Payments, and Liquidity.” Unpublished manuscript, Federal Reserve Bank of Chicago, 2009.

Nosal, Ed and Wallace, Neil. "A Model of (the Threat of) Counterfeiting.” Journal of Monetary Economics, May 2007, 54(4), pp. 994-1001.

Ostroy, Joseph M. and Starr, Ross M. "The Transactions Role of Money,” in Benjamin M. Friedman and Frank H. Hahn, eds., Handbook of Monetary Economics. Chap. 1. Amsterdam: North-Holland, 1990.

Pissarides, Christopher A. Equilibrium Unemployment Theory. Cambridge, MIT Press, 2000.

Ravikumar, B. and Shao, Enchuan. "Search Frictions and Asset Price Volatility." Working paper, University of Iowa, 2006.

Rocheteau, Guillaume. "A Monetary Approach to Asset Liquidity.” Working paper, University of CaliforniaIrvine, 2009.

Rocheteau, Guillaume and Wright, Randall. "Money in Search Equilibrium, in Competitive Equilibrium, and in Competitive Search Equilibrium.” Econometrica, January 2005, 73(1), pp. 175-202.

Rocheteau, Guillaume; Rupert, Peter; Shell, Karl and Wright, Randall. "General Equilibrium with Nonconvexities and Money.” Journal of Economic Theory, September 2008, 142(1), pp. 294-317. 
Rogerson, Richard. "Indivisible Labor, Lotteries, and Equilibrium.” Journal of Monetary Economics, January 1988, 21(1), pp. 3-16.

Samuelson, Paul A. "An Exact Consumption-Loan Model With or Without the Social Contrivance of Money." Journal of Political Economy, 1958, 66(6), pp. 467-82.

Sanches, Daniel and Williamson, Stephen. "Adverse Selection, Segmented Markets, and the Role of Monetary Policy.” Macroeconomic Dynamics, 2010a (forthcoming).

Sanches, Daniel and Williamson, Stephen. "Money and Credit with Limited Commitment and Theft." Journal of Economic Theory, 2010b(forthcoming).

Sargent, Thomas and Wallace, Neil. "'Rational' Expectations, the Optimal Monetary Instrument, and the Optimal Money Supply Rule.” Journal of Political Economy, April 1975, 83(2), pp. 241-54.

Sargent, Thomas and Wallace, Neil. "Rational Expectations and the Theory of Economic Policy." Journal of Monetary Economics, April 1976, 2(2), pp. 169-83.

Sargent, Thomas and Wallace, Neil. "Some Unpleasant Monetarist Arithmetic." Federal Reserve Bank of Minneapolis Quarterly Review, Fall 1981, 5(3).

Sargent, Thomas and Wallace, Neil. "The Real Bills Doctrine versus the Quantity Theory: A Reconsideration." Journal of Political Economy, December 1982, 90(6), pp. 1212-36.

Shi, Shouyong. "Money and Prices: A Model of Search and Bargaining." Journal of Economic Theory, December 1995, 67(2), pp. 467-96.

Shi, Shouyong. “A Divisible Search Model of Fiat Money.” Econometrica, January 1997, 65(1), pp. 75-102.

Shi, Shouyong. "Viewpoint: A Microfoundation of Monetary Economics." Canadian Journal of Economics, August 2006, 39(3), pp. 643-88.

Telyukova, Irina A. and Wright, Randall. "A Model of Money and Credit, with Application to the Credit Card Debt Puzzle.” Review of Economic Studies, April 2008, 75(2), pp. 629-47.

Tobin, James. "The Interest-Elasticity of Transactions Demand for Cash." Review of Economics and Statistics, August 1956, 38(3), pp. 241-7.

Tobin, James. "Liquidity Preference as Behavior Towards Risk.” Review of Economic Studies, February 1958, 25(2), pp. 65-86.

Tobin, James. "Discussion," in John Kareken and Neil Wallace, eds., Models of Monetary Economies. Minneapolis: Federal Reserve Bank of Minneapolis, 1980.

Townsend, Robert M. "Economic Organization with Limited Communication.” American Economic Review, December 1987, 77(5), pp. 954-70.

Townsend, Robert M. "Currency and Credit in a Private Information Economy.” Journal of Political Economy, December 1989, 97(6), pp. 1323-45.

Trejos, Alberto and Wright, Randall. "Search, Bargaining, Money, and Prices.” Journal of Political Economy, February 1995, 103(1), pp. 118-41.

Vayanos, Dimitri and Weill, Pierre-Olivier. "A Search-Based Theory of the On-the-Run Phenomenon.” Journal of Finance, June 2008, 63(3), pp. 1351-89.

Wallace, Neil. "The Overlapping Generations Model of Fiat Money,” in John Kareken and Neil Wallace, eds., Models of Monetary Economies. Minneapolis: Federal Reserve Bank of Minneapolis, 1980.

Wallace, Neil. “A Modigliani-Miller Theorem for Open Market Operations.” American Economic Review, June 1981, 71(3), pp. 267-74. 


\section{Williamson and Wright}

Wallace, Neil. “A Dictum for Monetary Theory.” Federal Reserve Bank of Minneapolis Quarterly Review, Winter 1998, 22(1), pp. 20-26.

Wallace, Neil. “Whither Monetary Economics?” International Economic Review, November 2001, 42(4), pp. 847-69.

Wallace, Neil. “The Mechanism Design Approach to Monetary Theory,” in Benjamin Friedman and Michael Woodford, eds., Handbook of Monetary Economics. Volume 3A. (forthcoming).

Wicksell, Knut. Lectures on Political Economy. Volume 2: Money. Translation by E. Classen. Second Edition. New York: Kelley, 1967.

Williamson, Stephen. "Costly Monitoring, Financial Intermediation, and Equilibrium Credit Rationing." Journal of Monetary Economics, September 1986, 18(2), pp. 159-79.

Williamson, Stephen. "Financial Intermediation, Business Failures, and Real Business Cycles.” Journal of Political Economy, December 1987a, 95(6), pp. 1196-216.

Williamson, Stephen. "Recent Developments in Modeling Financial Intermediation.” Federal Reserve Bank of Minneapolis Quarterly Review, Summer 1987b, 11(3), pp. 19-29.

Williamson, Stephen. "Private Money.” Journal of Money, Credit, and Banking, August 1999, 31(3), pp. 469-91.

Willliamson, Stephen. "Search, Limited Participation, and Monetary Policy." International Economic Review, February 2007, 47(1), pp.107-28.

Williamson, Stephen. "Liquidity, Financial Intermediation, and Monetary Policy in a New Monetarist Model." Working paper, Washington University in St. Louis, 2009.

Williamson, Stephen and Wright, Randall. "Barter and Monetary Exchange Under Private Information.” American Economic Review, March 1994, 84(1), pp. 104-23.

Williamson, Stephen and Wright, Randall. "New Monetarist Economics: Models,” forthcoming in Benjamin Friedman and Michael Woodford, eds., Handbook of Monetary Economics. Volume 3A. (forthcoming).

Woodford, Michael. Interest and Prices: Foundations of a Theory of Monetary Policy. Princeton, NJ: Princeton University Press, 2003.

Wright, Randall. “A Uniqueness Proof for Monetary Steady State.” Journal of Economic Theory, January 2010, 145(1), pp. 382-91.

Zhu, Tao. "Existence of a Monetary Steady State in a Matching Model: Indivisible Money." Journal of Economic Theory, October 2003, 112(2), pp. 307-24.

Zhu, Tao. "Existence of a Monetary Steady State in a Matching Model: Divisible Money." Journal of Economic Theory, August 2005, 123(2), pp. 130-60. 